\title{
Polysaccharides as Excipients for Ocular Topical Formulations
}

\author{
Ylenia Zambito and Giacomo Di Colo \\ University of Pisa \\ Italy
}

\section{Introduction}

The topical treatment of extraocular or intraocular diseases, especially by eye drops, is the best accepted by patients. Treatment with eye drops, however, poses the issue of a poor drug bioavailability because the precorneal area, i. e., the site of drug action/absorption, is rapidly cleared of drugs by protective mechanisms of the eye, such as blinking, basal and reflex tearing, and nasolachrymal drainage. This implies the need of frequent instillations, and hence, the risk of side effects. Increasing ocular bioavailability remains a stimulating challenge for the formulators of topical systems. An approach to the task has been the reduction of drainage rate by increasing the viscosity of liquid preparations (Lee \& Robinson, 1986) or resorting to mucoadhesive polymers (Hui \& Robinson, 1985). The ability of a polymer to improve the ocular bioavailability of drugs by adhering to the ocular surface and binding the drug to it is a more promising property than the polymer viscosifying power (Di Colo et al., 2009), so far as fluid solutions are better tolerated than viscous ones (Winfield et al., 1990). The ocular retention of drugs administered by eye drops is also potentially improved by colloidal drug carriers, such as liposomes, submicron emulsions, nanoparticles and nanocapsules. The drugs are incorporated into these submicron particles which can be internalized into the corneal and/or conjunctival cells of the ocular epithelium (Alonso \& Sanchez, 2009; Nagarwal et al., 2009). Prolonging the residence of drugs in the precorneal area serves either the extra- or intraocular therapy. In those cases where a well tolerated topical treatment is desired to implement an intraocular therapy, the ocular formulation can be made to contain an effective, biocompatible, non-irritant polymeric corneal permeability enhancer.

A description of the structures of the eye that come into contact with topical drug delivery systems has been reported recently (Ludwig, 2005). A summary is given in the next section, followed by an outline of the routes of intraocular drug penetration. Polysaccharides such as chitosan, xyloglucan, arabinogalactan, cellulose derivatives (methylcellulose, hydroxyethylcellulose, hydroxypropylmethylcellulose, sodium carboxymethylcellulose), hyaluronic acid, alginic acid, gellan gum, have been studied extensively as excipients for ocular formulations. In the present survey of the literature the relevant properties of polysaccharides will be presented and discussed, with emphasis on the functions of polymers in the ophthalmic formulations where they have been used. Only polysaccharides the ocular tolerability of which has been ascertained will be dealt with. 


\section{Anatomy and physiology of the eye}

\subsection{Structure of the ocular globe}

The human eye is schematically shown in Fig.1. The wall of the eyeball consists of an outer coat (sclera and cornea), a middle layer (uveal coat) and an inner coat (retina). The eyelids spread the tear fluid over the eye. The rate of shear during blinking (about 20,000 s-1) influences the rheological properties of instilled ophthalmic formulations and hence, drug bioavailability.

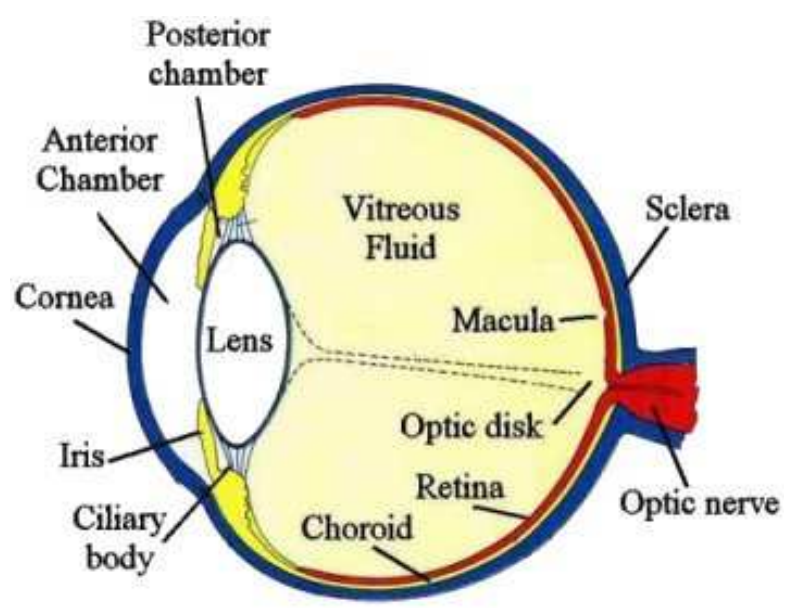

Fig. 1. Schematic view of the human eye

The cornea is a clear, avascular tissue composed of five layers: epithelium, Bowman's layer, stroma, Descemet's membrane and endothelium. The epithelium consists of 5-6 cell layers. The corneal epithelium is little permeable due to the presence of tight junctions connecting cells. High extracellular and low intracellular calcium levels are required for the low permeability of tight junctions. On the surface of the epithelium flattened cells are found microvilli which enhance the stability of the tear film.

The conjunctiva is a clear membrane, lining the inner surface of the eyelids, adjoining the corneal epithelium. The conjunctiva is vascularized and moistened by the tear film. Its epithelium is composed of 5-7 cell layers. The cells are connected by tight junctions, therefore the conjunctiva is impermeable to molecules larger than 20,000 Da, whereas the cornea is permeable up to $5000 \mathrm{Da}$.

A volume of about $2-3 \mu \mathrm{L}$ of mucus is secreted daily whereby foreign particles and bacteria are entrapped and swept by blinking to the drainage system for discharge. The turnover of the mucous layer $(15-20 \mathrm{~h})$ is much slower than that of the tear fluid.

\subsection{Nasolachrymal drainage system}

The tear fluid is spread on the ocular surface by blinking and collected by the canaliculi, the lachrymal sac and the nasolachrymal duct which opens into the inferior nasal passage. The tear fluid produced by the lachrymal gland is composed of the following:

1. Basic tearing $(0.5-2.2 \mu \mathrm{L} / \mathrm{min})$, needed to maintain a tear film on the corneal surface, corresponding to a turnover rate of $16 \% / \mathrm{min}$ while awake. 
2. Reflex tearing, caused by such stimuli as emotional, chemical or mechanical ones, cold temperature, light, which can raise lachrymation up to $300 \mu \mathrm{L} / \mathrm{min}$, thus clearing drugs away.

Undesired drug absorption through nasal mucosa can occur during drainage.

\subsection{Tear film}

The precorneal tear film (thickness 3-10 $\mu \mathrm{m}$; volume $\sim 10 \mu \mathrm{L}$ ) is composed of the following layers:

The superficial lipid layer (thickness $100 \mathrm{~nm}$ ), which spreads over the aqueous layer during eye opening. It contains such lipids as triglycerides, phospholipids, sterols, sterol esters, fatty acids, and helps tear fluid to maintain its normal osmolality by limiting evaporation.

The aqueous layer, which contains inorganic salts, glucose, urea, retinol, ascorbic acid, proteins, lipocalins, immunoglobulins, lysozyme, lactoferrin and glycoproteins. The tear fluid has an osmolality of $310-350 \mathrm{mOsm} / \mathrm{kg}$ and a mean $\mathrm{pH}$ of 7.4. Its buffering ability is determined by bicarbonate ions, proteins and mucins. The viscosity is $\sim 3 \mathrm{mPas}$, with a nonNewtonian rheological behaviour. The surface tension is $\sim 44 \mathrm{mN} / \mathrm{m}$.

The mucus layer, which forms a gel with viscoelastic properties. Mucins improve the spreading of the tear film and enhance its stability and cohesion. The mucus gel entraps bacteria, cell debris and foreign bodies forming bundles of thick fibers, which are conveyed by blinking to the inner canthus and expelled onto the skin. Mucus, which is charged negatively, can bind positively charged substances.

More recent studies have somewhat revised the above "three layers theory", proposing a 40$\mu \mathrm{m}$ thick film essentially made of mucus with an external lipid layer, but without a distinct thin aqueous layer. Mucus is made of glycoproteins (mucins), proteins, lipids, electrolytes, enzymes, mucopolysaccharides and water. As the polysaccharide side chains of mucins usually terminate in sialic acid (pKa 2.6) the mucins are negatively charged in physiological conditions. A combination of cross-linking via disulfide bridges and hydrophobic bonds and also through entanglements of randomly coiled macromolecules determines the tertiary structure of mucin.

Various factors influence the mucoadhesion of polymeric ocular delivery systems, linked to the composition, physicochemical properties and structure of the tear film. The polymer must come into intimate contact with the mucus layer. The polymer chains must be mobile and flexible enough to interpenetrate into the mucus to a depth sufficient to create a strong entangled network with mucin. The polymer and mucin should interact by hydrogen bonding, electrostatic and hydrophobic interactions which depend on the ionic strength and $\mathrm{pH}$ of the applied vehicle. Decreasing the $\mathrm{pH}$ enhances the mucoadhesion of polymers containing carboxyls because these groups preferentially interact with mucins in the unionized form via hydrogen bonding. On the other hand, the repulsion of carboxylate anions which form at higher $\mathrm{pH}$ values causes extension of polymer chains and decrease in density of such chains, which result in enhancement of chain mobility, interdiffusion and physical entanglement. Depending on the pKa of the functional groups of the polymer, either hydrogen bonding or entanglement prevails. Then, the precorneal residence of mucoadhesive polymers varies from a few hours to one day.

The tear film is not quite stable. In the short interval between blinks it ruptures with formation of dry spots on the cornea, which induces blinking and spreading of a new tear film. The breakup time of the tear film depends on dispersion forces, interfacial tension and 
viscous resistance of the mucus layer. These factors should be taken into account when developing mucoadhesive pharmaceutical systems.

\section{Routes of intraocular penetration}

Drugs penetrate across the epithelium into the eye via the transcellular (lipophilic drugs) or paracellular (hydrophilic drugs) route (Nanjawade et al., 2007). The main mechanism of transepithelial either transcellular or paracellular intraocular penetration of topically applied drugs is passive diffusion along their concentration gradients. The cornea provides the rate-limiting resistance against penetration of hydrophilic drugs, whereas partitioning from the epithelium into the hydrophilic stroma is the rate-liming factor for lipophilic drugs (Nanjawade et al., 2007). Permeation of ionizable drugs depends on the chemical equilibrium between ionized and unionized species in the tear fluid. The unionized species usually penetrates more easily than the ionized species. In the latter instance the type of charge affects transcorneal penetration. Indeed, the corneal epithelium is negatively charged, in physiological conditions ( $\mathrm{pH}$ 7.4), hence cationic drugs permeate more easily than anionic ones (Nanjawade et al., 2007). In addition to the corneal route, topically applied drugs may be absorbed via non-corneal routes. Hydrophilic and large molecules, showing poor corneal permeability, can penetrate across the bulbar conjunctiva and underlying sclera into the uveal tract and vitreous humor (Nanjawade et al., 2007). Tight junctions of the superficial conjunctival epithelium are wider than those in the cornea, therefore, the conjunctival permeability of hydrophilic drugs is generally significantly higher than their corneal permeability (Nanjawade et al., 2007). However, the conjunctiva is vascularized, therefore it is generally considered a site for systemic, hence, unproductive absorption.

\section{Polysaccharides in ocular formulations}

The use of natural polysaccharides in ocular formulations is attractive as these products are economical, readily available, non-toxic, potentially biodegradable, generally biocompatible and capable of chemical modifications. Such modifications have recently led to derivatives with improved biopharmaceutical performances, e.g. rhelogical behavior, mucoadhesivity, ability to enhance corneal permeability, easy solubilization.

\subsection{Chitosan and its derivatives}

Chitosan (Ch) is a linear polysaccharide composed of randomly distributed $\beta$-(1-4)-linked Dglucosamine (deacetylated unit) and N-acetyl-D-glucosamine (acetylated unit) (Fig.2).

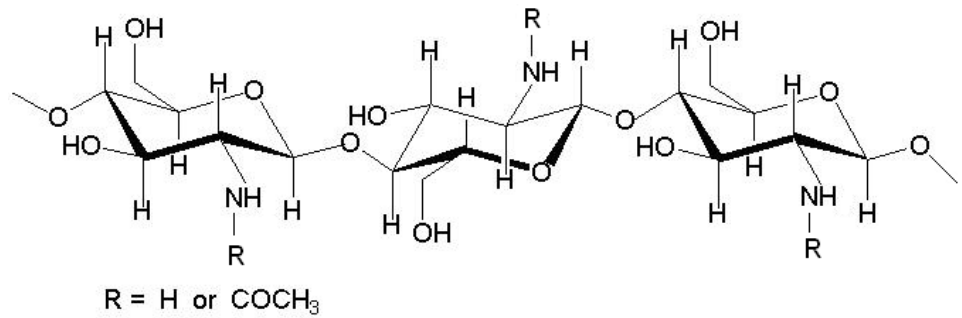

Fig. 2. Chitosan structure 
Ch is produced commercially by deacetylation of chitin, which is the structural element in the exoskeleton of crustaceans (crabs, shrimps, etc.) and cell walls of fungi. The degree of deacetylation in commercial Chs is in the range of $60-100 \%$. The tremendous potential of $\mathrm{Ch}$ in the pharmaceutical area is illustrated in several review articles (Alonso \& Sanchez, 2009; Nagarwal et al., 2009; Dodane \& Vilivalam, 1998; Felt et al., 1998; Paul \& Sharma, 2000; Singla \& Chawla, 2001, Di Colo et al., 2008). These point out that Ch is biodegradable, has low toxicity and good ocular tolerability, exhibits bioadhesion and permeability-enhancing properties and also physico-chemical characteristics that make it suitable for the design of ocular drug delivery vehicles. The $\mathrm{Ch}$ repeating unit bears a primary amino group bestowing a reactivity on the polymer that allows its transformation into derivatives of interest as biocompatible and bioactive excipients for ophthalmic drug delivery systems (Di Colo et al., 2004a; Zambito et al., 2006a; Zambito et al., 2007). Over the last decade efforts have been made to put into evidence the ability of Ch to safely promote intraocular drug penetration by enhancing corneal permeability, and to synthesize $\mathrm{Ch}$ derivatives with improved such bioactivity. The significant results of these efforts will be discussed in the next subsections.

\subsubsection{Eye drops}

The main role of $\mathrm{Ch}$ in ocular solutions was to improve ocular drug bioavailability by prolonging drug residence in precorneal area in virtue of polymer mucoadhesivity and effect on viscosity (Alonso \& Sancez, 2009). More recently Ch solutions have been investigated for their ability to improve intraocular drug bioavailability, following topical administration, by enhancing corneal permeability. Although the ability of $\mathrm{Ch}$ to permeabilize nasal mucosa and intestinal epithelium has been known since 1994 (Illum et al., 1994; Artursson et al., 1994) the permeabilizing effect of this polymer applied via eye drops on the cornea was demonstrated for the first time ten years later (Di Colo et al., 2004b). Unlike the intestinal and nasal epithelia, both made of a single layer of cells joined by tight junctions, the cornea is a stratified epithelium the cells of which also are joined by tight junctions. Therefore, the ability of $\mathrm{Ch}$ to enhance the permeability of intestinal and nasal epithelia would not necessarily imply a similar effectiveness on the corneal epithelium.

Instead of using the excised cornea, as in previous studies of the enhancement of corneal permeability to drugs, the permeabilizing effect of Ch was investigated in vivo (Di Colo et al., 2004b) . To this purpose, ofloxacin was instilled into the eyes of albino rabbits via isoviscous eye drops containing $\mathrm{Ch}$ hydrochloride $(\mathrm{Ch}-\mathrm{HCl})$, or $\mathrm{N}$-carboxymethyl $\mathrm{Ch}$ (CMCh) (Muzzarelli et al., 1982), or poly(vinyl alcohol) (PVA), and the resulting pharmacokinetics in tear fluid and aqueous humor were determined (Di Colo et al., 2004b). $\mathrm{CMCh}$, a polyanion at the physiological $\mathrm{pH}$ of the tear fluid (Fig.3), was tested to ascertain the relevance of the polycationic nature of $\mathrm{Ch}-\mathrm{HCl}$ and because $\mathrm{CMCh}$ was claimed to behave as an intestinal absorption enhancer (Thanou et al., 2001).

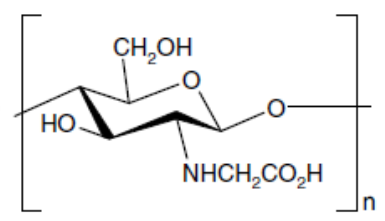

Fig. 3. Structure of $N$-carboxymethyl chitosan. 
Only small differences among the rates of drug disappearance from tear fluid were measured for the three solutions, reflecting the small differences among the respective viscosity values. Such values were high enough to ensure the presence of drug in tear fluid at measurable concentrations after about $1.5 \mathrm{~h}$ of instillation. Although the time of drug residence in the precorneal area was almost the same for the three solutions containing Ch$\mathrm{HCl}, \mathrm{CMCh}$ or PVA, the respective pharmacokinetic data for the aqueous humor were neatly distinct. This was taken as a sign of different effects of polymers on the corneal permeability. PVA produced an increase of $t_{\max }$ with respect to the reference Exocin ${ }^{\circledR}$, which was ascribed to the increased viscosity of the PVA solution with respect to the commercial eye drops, causing a reduction of tear fluid drainage, and hence, of the precorneal elimination rate. This polymer, however, produced no permeabilization of the cornea, indeed, there was no significant increase of neither concentration peak $\left(C_{\max }\right)$ nor bioavailability (AUC) in the aqueous. On the other hand, $\mathrm{Ch}-\mathrm{HCl}$ produced $\mathrm{C}_{\max }$ and $\mathrm{AUC}$ values remarkably higher than the respective values for the reference, at the same $t_{\max }$. Then unlike the case of PVA, with $\mathrm{Ch}-\mathrm{HCl}$ the increased viscosity of the solution was found to cause no prolongation of $t_{\max }$. These pharmacokinetic data were taken as indicative of an increase of the corneal absorption rate constant, due to an enhancement of corneal permeability by $\mathrm{Ch}-\mathrm{HCl}$.

More recently the effects of $\mathrm{Ch}$ and other non-polymeric permeabilizers on the permeation of acyclovir across excised rabbit cornea have been studied (Majumdar et al., 2008). Ch was solubilized at the concentration of 0.1 or $0.2 \%$ by $2 \%$ acetic acid added to Dulbecco's phosphate buffered saline. The apparent corneal permeability $\left(\mathrm{P}_{\text {app }}\right)$ was determined by normalizing the permeant flux to the permeant concentration in the donor. In the presence of 0.2 and $0.1 \%$ Ch the transcorneal acyclovir permeability was enhanced almost 5.8-fold $\left(7.61 \times 10^{-6} \mathrm{~cm} / \mathrm{s}\right)$ and 3.1 -fold $\left(4.1 \times 10^{-6} \mathrm{~cm} / \mathrm{s}\right)$, respectively, over that of acyclovir alone $\left(1.32 \times 10^{-6} \mathrm{~cm} / \mathrm{s}\right)$.

The use of unmodified $\mathrm{Ch}$ in eye drops as a cornea-permeabilizing agent is not quite rational because of problems with its solubility in tear fluid at the physiological $\mathrm{pH}$ of 7.4. Although $\mathrm{Ch}-\mathrm{HCl}$ is in the dissolved, and hence, bioactive state just as applied, yet its permeability-enhancing effect is presumably temporary. Indeed Ch requires $\mathrm{pH} \leq 5$ for dissolution, hence it is expected to precipitate as the free base some time after instillation, as soon as the physiological $\mathrm{pH}$ of the tear fluid is restored. For this reason the effect of $\mathrm{CMCh}$, a polyanionic $\mathrm{Ch}$ derivative soluble at this $\mathrm{pH}$ (Fig.3), on transcorneal drug absorption is of particular relevance. Although $\mathrm{CMCh}$ was found to behave as an intestinal absorption enhancer (Thanou et al., 2001) , it failed to significantly enhance corneal permeability, in fact, the drug levels produced in the aqueous by $\mathrm{CMCh}$ never exceeded the $\mathrm{C}_{\max }$ for the reference Exocin $^{\circledR}$ (Di Colo et al., 2004b). Then it appears that the polycationic nature of Ch is essential to its permeabilizing effect on the cornea. Interestingly, however, the drug concentration in the aqueous vs. time data relative to $\mathrm{CMCh}$ pointed to zero-order transcorneal absorption kinetics. This observation prompted the hypothesis that $\mathrm{CMCh}$ might mediate a pseudosteady-state transcorneal transport, via polymer interactions with the drug and polymer adhesion to the corneal mucus (Di Colo et al., 2004b). Such a mucoadhesion could prolong the drug residence at the absorption site. Despite the different effects of $\mathrm{Ch}-\mathrm{HCl}$ and $\mathrm{CMCh}$ on ofloxacin ocular pharmacokinetics, these polymers increased the drug intraocular bioavailability with respect to the reference by about the same factor, as shown by the relevant AUC values. $\mathrm{CMCh}$, being a polyanion, is potentially able to bind cationic drugs. Then it can prolong the precorneal residence of, e.g., aminoglucoside antibiotics at effective antimicrobial concentrations, thus allowing reduction of the frequency of instillations. 
Polycationic derivatives of $\mathrm{Ch}$, soluble in tear fluid at the physiological $\mathrm{pH}$ of 7.4, can have an increased potential for enhancing the corneal permeability (Di Colo et al., 2004a). A similar derivative, i.e., $N$-trimethylchitosan (TMC), has been obtained by quaternizing the primary amino group of $\mathrm{Ch}$ with methyl iodide, thus bestowing fixed, $\mathrm{pH}$-independent positive charges on the polymer (Fig.4). The complete quaternization is unnecessary to make the polymer soluble at neutral or alkaline $\mathrm{pH}$, in fact, a quaternization degree (QD) of around $40 \%$ is sufficient for this purpose (Snyman et al., 2002; Di Colo et al., 2004a). TMC has proved a potent permeation enhancer of hydrophilic molecules and macromolecules across the intestinal epithelium in neutral environments (Kotzé et al., 1997; Kotzé et al., 1998; Thanou et al., 2000). A study of the enhancing effects of TMC polymers having varying QD on the permeation of the hydrophilic mannitol or PEG 4000 across epithelial cell monolayers (Caco-2) demonstrated the existence of an optimum QD, beyond which the permeability was no further increased (Hamman et al., 2003).

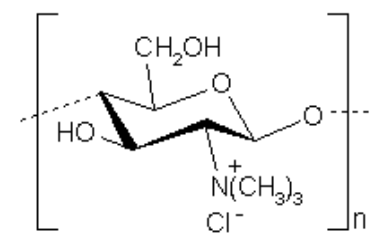

Fig. 4. Structure of $N$ - trimethylchitosan.

It has been shown that TMC is able to enhance the permeability of the rabbit corneal epithelium reconstituted in vitro (RRCE) to ofloxacin. A dependence of such a permeabilizing ability on the QD of TMC, similar to that found previously with the Caco-2 intestinal epithelium model (Hamman et al., 2003), has been evidenced (Di Colo et al., 2004a). The steady-state flux of ofloxacin across the RRCE in the presence of TMCs having different QDs was measured and $\mathrm{P}_{\text {app }}$ values were calculated by dividing such a flux by the drug concentration in the applied solution $(0.001 \% \mathrm{w} / \mathrm{v}$, not cytotoxic to the RRCE cells). The $\mathrm{P}_{\text {app }}$ enhancement was calculated as the ratio of the $\mathrm{P}_{\text {app }}$ value in the presence to that in the absence of polymer (enhancement ratio, ER). TMC polymers having low QD (3-4\%) were barely soluble and ineffective, whereas those having intermediate QD (35-45\%) were soluble and significantly bioactive (ER 1.5-1.6). TMC polymers having high QD (80-90\%) showed no further increase of permeability (ER 1.5) (Di Colo et al., 2004a). To explain these findings the following hypotheses may be put forward (Di Colo et al., 2004a; Hamman et al., 2003). At intermediate QD TMC has favorable chain flexibility and conformation whereas at higher QD the TMC electrostatic interactions with the epithelial cell membrane may be hindered by steric effects of the attached methyl groups. Another explanation may be the saturation of the interaction sites on the membrane. A polycationic polysaccharide, i.e., the fully quaternized N-methyl-diethylaminoethyl dextran (MeDEAED) was tested for its ability to permeabilize the RRCE. Although MeDEAED has similar charge density and molecular weight as the TMC having QD $80 \%$, yet only the latter produced a significant $\mathrm{P}_{\text {app }}$ increase on the RRCE (Di Colo et al., 2004a). This means that charge density and MW are not the sole properties of Chs that concur to determine the ability of these polysaccharides to promote transcorneal drug absorption. 
The TMC polymers with intermediate QD, which had proven effective on the RRCE, were also tested in vivo, in the eyes of albino rabbits. The polymers were synthesized from Chs of MW $580 \mathrm{kDa}(\mathrm{TMCL})$ and $1460 \mathrm{kDa}(\mathrm{TMCH})$, respectively, in order to investigate the relevance of MW to the polymer bioactivity. The pharmacokinetic data for ofloxacin obtained in the presence of these derivatives were compared with those obtained with Ch$\mathrm{HCl}$ (Di Colo et al., 2004a; Di Colo et al., 2004b). For making these comparisons indicative of the relative bioactivity of polymers all solutions were made isoviscous using PVA, which had been shown to be inert on the cornea (Di Colo et al., 2004b). A significant enhancement of transcorneal absorption rate was produced by $\mathrm{TMCH}$, i.e., the $\mathrm{Ch}$ derivative with higher MW, through an increase of corneal permeability, as could be deduced from increases of drug bioavailability and peak concentration in the aqueous (AUC and $\mathrm{C}_{\max }$, respectively) by $283 \%$ and $318 \%$, respectively, over the control. Such an enhancement was also indicated by a shortening of the time to peak ( $\mathrm{t}_{\max }$ ). In the presence of TMCH the $\mathrm{C}_{\max }$ exceeded $4 \mu \mathrm{g} / \mathrm{ml}$, which is the $\mathrm{MIC}_{90 \%}$ for the more resistant ocular pathogens (Taravella et al., 1999). On the basis of this consideration, TMCH can be regarded as a potential absorption enhancer to be formulated into ophthalmic ofloxacin solutions for the topical treatment of endophthalmitis. A comparison of the data for $\mathrm{TMCH}$ with those for $\mathrm{Ch}-\mathrm{HCl}$ showed that the permeabilizing effect of the partially quaternized derivative is stronger that that of the hydrochloride of unmodified Ch. This was indeed predicted in the foregoing discussion on the basis of considerations about polymer solubility. Data for TMCL showed that for this derivative $\mathrm{C}_{\max }$ was significantly lower and $t_{\max }$ longer than the corresponding values for $\mathrm{TMCH}$, which points to a weaker enhancing effect of TMCL. The stronger effect of the derivative having the higher MW was ascribed to its stronger adhesion to the corneal mucus (Di Colo et al., 2004a). Indeed it was reported that mucoadhesion, along with the opening of tight junctions, is a key element of TMC polymers for being effective as absorption enhancers at mucosal surfaces (Snyman et al., 2003).

The absorption-enhancing efficacy of TMC was thought to depend on its charge density which, in neutral or alkaline environments, is determined by its quaternization degree (Hamman et al., 2003). In the light of this consideration, novel chitosan derivatives with pendant quaternary ammonium groups were prepared by reacting $\mathrm{Ch}$ with 2diethylaminoethyl chloride (DEAE-Cl) under different conditions (Zambito et al., 2006b). The general structure of these derivatives, assessed by NMR analysis, is depicted in Fig.5.
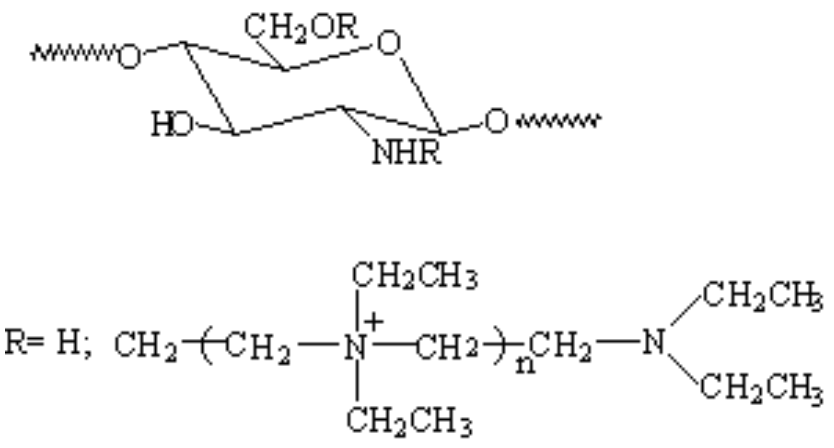

Fig. 5. Structure of N,O-[N,N-diethylaminomethyl(diethyldimethylene ammonium) ${ }_{n}$ methyl] chitosans. 
They are assigned the general code, $\mathrm{N}^{+}-\mathrm{Ch}$, referring to their nature of quaternary ammonium $\left(\mathrm{N}^{+}\right)$-chitosan $(\mathrm{Ch})$ conjugates. The degree of substitution by the pendant chain (DS) and the mean number of quaternary ammonium groups in the chain (n) depend on the MW of the starting $\mathrm{Ch}$ and on the molar ratio between reactant (DEAE-Cl) and $\mathrm{Ch}$ repeating unit, used in the synthesis. A Ch from shrimp shell (MW=590 kDa), with a reagent excess of 4:1 yielded a derivative, $\mathrm{N}^{+}-\mathrm{Ch}-4$, with values of the parameters, DS and $\mathrm{n}$, higher than those of $\mathrm{N}^{+}-\mathrm{Ch}-2$, obtained with a reagent excess of $2: 1(\mathrm{DS}=132, \mathrm{n}=2.5$ vs. $\mathrm{DS}=40, \mathrm{n}=1.6)$. The transcorneal penetration-enhancing properties of $\mathrm{N}^{+}-\mathrm{Ch}-2$ and $\mathrm{N}^{+}-\mathrm{Ch}-4$ were tested ex vivo on the excised rabbit cornea, using the lipophilic dexamethasone and the hydrophilic fluorescein sodium as permeabilization probes (Zambito et al., 2007). The results were compared with corresponding data obtained with a TMC having a QD of $46 \%$, synthesized from the same $\mathrm{Ch}$ as that used to prepare the $\mathrm{N}^{+}-\mathrm{Ch}$ conjugates. Dexamethasone was applied on the cornea as a suspension, hence the relevant $P_{\text {app }}$ values were calculated by dividing the steady-state flux by the drug aqueous solubility. A significant binding of fluorescein to the Ch derivatives was measured by a dynamic dialysis technique, so the concentration of free fluorescein applied to the cornea was used to calculate the relevant $\mathrm{P}_{\text {app }}$.

TMC and the $\mathrm{N}^{+}-\mathrm{Ch}$ derivatives of whichever DS and $\mathrm{n}$, each at the concentration of $1 \%$ $\mathrm{w} / \mathrm{v}$, enhanced the $\mathrm{P}_{\text {app }}$ of the hydrophobic dexamethasone across the excised cornea to about the same extent. On the other hand the $E R$ value for the hydrophilic probe fluorescein sodium was the lowest with $\mathrm{N}^{+}-\mathrm{Ch}-2$ (the less substituted), intermediate with TMC, and the highest with $\mathrm{N}^{+}-\mathrm{Ch}-4$ (the more substituted). The apparent difference between the polymer effects on the corneal permeability of dexamethasone and fluorescein reflects the difference in the corneal structures on which the effects were probably exerted, that is, the membrane of the corneal cells, in the case of dexamethasone, and the tight junctions connecting the corneal cells, in the case of fluorescein (Zambito et al., 2007).

$\mathrm{N}^{+}-\mathrm{Ch}-4$ has been tested for its ability to promote the intraocular penetration of dexamethasone or fluorescein in vivo, in rabbit eyes (Zambito et al., 2007). The intraocular availability of dexamethasone was much higher than that of fluorescein in the reference eye drops. This reflected a much better partitioning of the lipophilic dexamethasone in the corneal cell membrane. In fact, fluorescein transcorneal penetration from the reference eye drops was almost insignificant essentially because of a poor partitioning of the permeant in the cornea. $\mathrm{N}^{+}-\mathrm{Ch}-4$ significantly enhanced intraocular absorption of fluorescein. In fact the results of the ex vivo and in vivo experiments agree in indicating a much stronger enhancement effect of this polymer on fluorescein than on dexamethasone. Yet the enhanced $P_{a p p}$, AUC and $C_{\max }$ values for fluorescein, which reflect the enhanced availability of this highly polar drug model in the aqueous humor, remained lower than the respective values for the non-polar dexamethasone. This means that the paracellular route across the cornea, which is the more likely for very polar molecules, such as fluorescein sodium, remains difficult to penetrate despite the permeabilizing action of the $\mathrm{Ch}$ derivatives. On the other hand the use of such enhancers as TMC and $\mathrm{N}^{+}-\mathrm{Ch}$ conjugates may turn profitable for improving the effectiveness of existing commercial ophthalmic formulations of such drugs as dexamethasone and ofloxacin.

As in the cases of protonated or quaternized Chs, the activity of which as epithelial permeability enhancers is now well documented (see, e.g., Di Colo et al., 2008), an electrostatic interaction with negatively charged sites in the mucus, on the cell membranes, or in the tight junctions joining epithelial cells is supposed to be at the basis of the bioactivity of the $\mathrm{N}^{+}-\mathrm{Ch}$ conjugates. The more significant representatives of these derivatives 
are characterized by degrees of substitution of $40-60 \%$ (Zambito et al., 2008). The comparatively high fraction of free, unsubstituted primary amino groups still available on the polymer backbone has been used for covalent attachment of thiol-bearing compounds, via formation of 3-mercaptopropionamide moieties. This has led to water-soluble thiolated quaternary ammonium-Ch conjugates $\left(\mathrm{N}^{+}-\mathrm{Ch}-\mathrm{SH}\right)$ the epithelial permeability-enhancing potential of which was tested using the Caco-2 cell monolayer and the excised rat jejunum as substrates (Zambito et al., 2009). On the basis of the obtained results the quaternary ammonium groups of these derivatives were ascribed the ability to reversibly open the epithelial tight junctions and also perturb the plasma membrane of the epithelial cells. On their part the thiol groups were believed to keep the polymer adherent to the epithelium by reacting with the thiols of the epithelial mucus to form disulphide bonds thus favouring the permeability-enhancing action of the positive ions. An $\mathrm{N}^{+}$-Ch conjugate with $\mathrm{DS}=60 \%$ and $\mathrm{n}=1.7$ was used to synthesize a multifunctional non-cytotoxic thiomer carrying $4.5 \%$ thiolbearing 3-mercaptopropionamide besides quaternary ammonium groups (Fig.6).

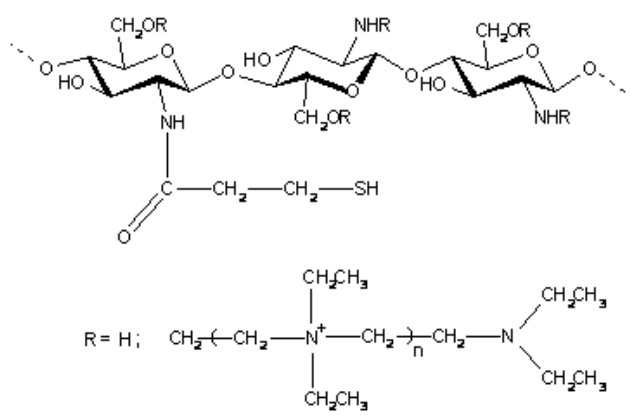

Fig. 6. Strcture of thiolated quaternary ammonium-Ch conjugates

The potential of this $\mathrm{N}^{+}-\mathrm{Ch}-\mathrm{SH}$ thiomer and the parent $\mathrm{N}^{+}-\mathrm{Ch}$ as bioactive excipients for dexamethasone eye drops was evaluated. The drug permeability across excised rabbit cornea was enhanced over the control value by the thiomer and the parent polymer to about the same extent ( 3.8 vs. 4.1 times). The mean precorneal retention time (MRT) and AUC in the aqueous of dexamethasone instilled in rabbit eyes via eye drops were enhanced by the thiomer $\left(\mathrm{MRT}=77.96 \pm 3.57 \mathrm{~min}, \mathrm{AUC}=33.19 \pm 6.96 \mu \mathrm{g} \mathrm{ml}^{-1} \mathrm{~min}\right)$ more than the parent polymer (MRT=65.74 $\pm 4.91 \mathrm{~min}, \mathrm{AUC}=21.48 \pm 3.81 \mu \mathrm{g} \mathrm{ml}^{-1} \mathrm{~min}$ ) over the control $(\mathrm{MRT}=5.07 \pm 0.25 \mathrm{~min}$, AUC $\left.=6.25 \pm 0.65 \mu \mathrm{g} \mathrm{ml}^{-1} \mathrm{~min}\right)$. The quaternary ammonium ions were responsible for both permeabilization of corneal epithelium and polymer adhesion to precorneal mucus, while the thiols increased the latter. This synergistic action is the basis of the higher thiomer bioactivity in vivo (Zambito \& Di Colo, 2010).

\subsubsection{In situ-gelling systems}

It is now known that prolonged-release ocular inserts, though causing some discomfort to patients, can remarkably increase the drug ocular bioavailability with respect to the traditional eye drops (Saettone \& Salminen, 1995; Di Colo et al., 2001a; Di Colo et al., 2001b). It was found that ocular inserts based on poly(ethylene oxide) (PEO) immediately after application in the lower conjunctival sac of the rabbit eye formed mucoadhesive gels, well 
tolerated by the animals; then the gels spread over the corneal surface and eroded (Di Colo et al., 2001a; Di Colo et al., 2001b). In order to evaluate the potential of Ch as an intraocular drug absorption promoter ofloxacin was selected as a drug of practical interest and $\mathrm{Ch}-\mathrm{HCl}$ microspheres medicated with this drug were dispersed into PEO (MW $900 \mathrm{kDa}$ ) in the PEO$\mathrm{Ch}-\mathrm{HCl}$ (9:1) wt proportion. Erodible ocular inserts, each containing a dose of $0.3 \mathrm{mg}$ ofloxacin, were obtained by compression of the mixture. They were fairly tolerable in the precorneal area of rabbits. The ofloxacin concentration profiles in the aqueous, following administration of a $0.3 \mathrm{mg}$ dose by the PEO-Ch- $\mathrm{HCl}(9: 1)$ insert, or a medicated PEO insert not containing $\mathrm{Ch}-\mathrm{HCl}$, or commercial Exocin eye drops were obtained along with the relevant pharmacokinetic data $\left(\mathrm{C}_{\max }, \mathrm{t}_{\max }\right.$, AUC) (Di Colo et al., 2002).

As expected, the inserts produced remarkable (one order of magnitude) increases of the AUC values, hence of intraocular bioavailability, over the commercial eye drops. The medicated $\mathrm{Ch}-\mathrm{HCl}$ microspheres dispersed in the $\mathrm{PEO}$ insert produced no substantial bioavailability change with respect to the plain PEO insert. However, with the PEO-Ch- $\mathrm{HCl}$ (9:1) insert the $C_{\max }$ value was significantly increased over that produced by the $\mathrm{Ch}-\mathrm{HCl}$-free PEO insert (7.16 \pm 0.77 vs. $\left.4.39 \pm 0.58 \mu \mathrm{g} \mathrm{ml}^{-1}\right)$, while the $t_{\max }$ was reduced (150 vs. $\left.300 \mathrm{~min}\right)$. It was reasoned that $\mathrm{Ch}-\mathrm{HCl}$, once in contact with the cornea, could exert a gradual enhancing effect on the corneal permeability which could explain the above data (Di Colo et al., 2002). Microspheres of TMC, medicated with dexamethasone or tobramycin sulfate, were dispersed into PEO (MW $900 \mathrm{kDa}$ ) inserts with the aim of both maximizing the intraocular bioavailability of the drugs and studying the permeabilizing effects of TMC on the cornea (Zambito et al., 2006a). Introduction of 10\% TMC microspheres into PEO inserts did not substantially affect the drug release pattern and rate from vehicle, nor the vehicle residence time in the precorneal area of rabbits. This allowed assessing the TMC effect on corneal permeability simply by comparing the concentration vs. time profiles in the aqueous obtained with the TMC-containing and the TMC-free inserts. The presence of TMC in the insert significantly increased $C_{\max }\left(5.69 \pm 0.49\right.$ vs. $\left.3.07 \pm 0.31 \mu \mathrm{g} \mathrm{ml}^{-1}\right)$ and AUC (619.3 \pm 32.5 vs. $380.5 \pm 32.0 \mu \mathrm{g} \mathrm{ml}^{-1} \mathrm{~min}$ ) for a dose of $0.3 \mathrm{mg}$ of the lipophilic dexamethasone, indicating an enhancement effect of TMC on the transcellular penetration pathway. This effect could be exerted through an interaction with the glycoproteins of the mucous layer covering the cornea and/or with the lipid bilayer of the corneal cell membrane (Zambito et al., 2006a). In fact, interactions of protonated chitosan with model phospholipid membranes have been reported (Chan et al., 2001; Fang et al., 2001). A comparison of pharmacokinetic data for an equal dose of the dexamethasone administered as eye drops $\left(C_{\max }=0.21 \pm 0.02 \mu \mathrm{g} \mathrm{ml}-1\right.$; AUC $=17.1 \pm 0.1 \mu \mathrm{g} \mathrm{ml}^{-1} \mathrm{~min}$ ) with those obtained with the inserts shows a tremendous potential of inserts for maximizing intraocular drug availability. This compensates for the moderate discomfort in situ gel-forming inserts may cause to patients. On the other hand, the tobramycin concentration in the aqueous was below the limit of detection, even with the TMC-containing insert. It is known that TMC is able to enhance the paracellular penetration of hydrophilic molecules or macromolecules across cell monolayers, such as the intestinal epithelium, by opening the tight junctions between cells (Kotzé et al., 1997; Kotzé et al., 1998; Thanou et al., 2000). The results obtained with tobramycin (Zambito et al., 2006a) demonstrate that the tight junctions of such a stratified epithelium as the cornea are not effectively opened by TMC, at least to such an extent as to allow therapeutically effective penetration of hydrophilic drugs of the tobramycin molecular size. If the cornea is virtually impermeable to tobramycin, although the external cell layer might be affected by TMC the 
deeper layers could remain impervious to this drug. On the other hand, dexamethasone could effectively permeate the cornea, hence the TMC action, although exerted on the corneal surface, could significantly enhance the apparent permeability of this drug.

In the foregoing discussion it was shown that the transcorneal penetration of a paracellular marker, such as fluorescein sodium, was significantly promoted by the polycationic $\mathrm{Ch}$ derivatives TMC and $\mathrm{N}^{+}-\mathrm{Ch}$, although the enhanced flux remained comparatively low. These results can be reconciled with those currently discussed concerning tobramycin by considering that the enhancing effect could be measured in the case of fluorescein, but not in that of tobramycin, because the detection limit of the analytical method for the former was much lower than for the latter $\left(8 \times 10^{-3}\right.$ vs. $\left.0.5 \mu \mathrm{g} / \mathrm{ml}\right)$. In the light of the discussion so far, the remarkable promotion of the transcorneal absorption of ofloxacin by TMC (Di Colo et al., 2004a) is ascribable to a polymer action on the mucous layer covering the cornea and/or on the corneal cell membrane, rather than to an effective opening of the tight junctions in all layers of corneal cells.

To overcome the bioavailability problems associated with the administration of conventional eye drops the use of in situ gel-forming systems that are instilled as drops into the eye and undergo a sol-gel transition in the cul-de-sac has been proposed (Gupta et al., 2007). Different combinations of Ch (MW $150 \mathrm{kDa}, 75-85 \%$ deacetylated) and poloxamer (Pluronic F-127) were evaluated for gelling ability and viscosity. The selected formulation ( $0.25 \%$ chitosan, $9.0 \%$ Pluronic F-127) had a viscosity that could allow easy instillation into the eye as drops and rapid sol-to-gel transition in the precorneal area triggered by a rise in $\mathrm{pH}$ from 6.0 to 7.4 and in temperature from ambient to $35-37{ }^{\circ} \mathrm{C}$. A $0.25 \%$ timolol concentration usually prescribed for the therapy of glaucoma was added to the formulation. This was a clear, isotonic solution having $\mathrm{pH}$ 6.0-6.2. The formulation was converted into a stiff gel during autoclaving but recovered its original properties after cooling. Transcorneal permeation was studied ex vivo using excised goat corneas. The authors report a larger drug amount permeated after $4 \mathrm{~h}$ with the in situ gelling system $(63.41 \pm 2.6 \%)$ as compared with the plain drug solution $(42.11 \pm 2.1 \%$ ) (Gupta et al., 2007) . They ascribe this difference to a permeabilizing action of $\mathrm{Ch}$ on the cornea, on the basis of the renown of $\mathrm{Ch}$ as a transmucosal permeation enhancer. It should be considered, however that the comparison between gelling system and control is based on the cumulative permeation and not on the $\mathrm{P}_{\text {app }}$ value. Then factors other than corneal permeability might contribute to the difference. Ocular irritation was tested by the chick embryo chorioallantoic membrane test (Gupta et al., 2007). It was found that the in situ gel formulation is nonirritant to mildly irritant and is well tolerated. In vivo precorneal drainage of the formulation was assessed by gamma scintigraphy, using albino rabbits for the study. The observation of the acquired gamma camera images showed good spreading of the in situ-gelling system over the entire precorneal area immediately after administration. The curve of the remaining activity on the corneal surface as a function of time showed that the plain drug solution cleared very rapidly from the corneal region. The drug passed into the systemic circulation, as significant activity was recorded in kidney and bladder $2 \mathrm{~h}$ after ocular administration. On the other hand the in situ gel formulation cleared slowly and no radioactivity was observed in kidney and bladder. This behaviour was ascribed to the known bioadhesivity of $\mathrm{Ch}$ and to the gelation that was induced by $\mathrm{Ch}$ and Pluronic F-127 (Gupta et al., 2007).

Another in situ gel-forming solution was obtained by coupling poly( $N$-isopropylacrylamide) (PNIPAAm), a well-known thermosensitive polymer having a thermoreversible phase 
transition temperature close to human body surface (Maeda et al., 2006; Taylor \& Ceranaowski, 1975; Hsiue et al., 2002; Hsiue et al., 2003), with Ch with the hope that this novel polymer (PNIPAAm-Ch) might couple the advantages of $\mathrm{Ch}$ and PNIPAAm (Cao et al., 2007). The ocular pharmacokinetics of timolol maleate, applied by this thermosensitive gel-forming system, were measured by microdialysis, a technique for continuously monitoring the drug in the rabbit aqueous (Wei et al., 2006; Macha \& Mitra, 2001; Rittenhouse et al., 2000). By means of the sampling technique the behaviour of the drug was studied after the gel-forming solution and the conventional eye drops, both at the concentration of $0.5 \%$, were administered in the cul-de-sac. The peak concentrations of 5.58 and $11.2 \mathrm{ng} / \mathrm{ml}$ were reached in the aqueous 15 and $30 \mathrm{~min}$ after instillation of the conventional eye drops and the thermosensitive gel-forming solution, respectively. It was also noted that the AUC for the latter was two-fold greater than that for the former. These data suggested that the gel-forming system improved the intraocular bioavailability and effectiveness of timolol maleate, which was embedded in the gel and therefore retained in the pre-corneal area for a prolonged period. As a hypothesis from the authors, however not substantiated by further data, PNIPAAm-Ch might enhance the corneal permeability and absorption of timolol maleate due to its positive charge and adhesive characteristics. The MTT assay showed little cytotoxicity of PNIPAAm-Ch at concentrations in the 0.5-400 $\mu \mathrm{g} / \mathrm{ml}$ range (Cao et al., 2007).

\subsubsection{Ch-based colloidal drug carriers}

The potential of colloidal drug carriers, such as liposomes, submicron emulsions, nanocapsules and nanoparticles in ocular delivery has been put into evidence by a review article in 2009 (Alonso et al., 2009). It has been shown that the action of Ch-based nanoparticle systems relies on particle interactivity with the corneal or conjunctival epithelium cells. The nanoparticles can be uptaken within the epithelial cells without causing any damage to them. In this way these nanosystems, once loaded with drugs, might make the conjunctival and corneal epithelia reservoirs for drug delivery to the exterior or interior of the eye. The interaction between $\mathrm{Ch}$ nanoparticles and the corneal and conjunctival epithelial surfaces have been investigated (Lehr et al, 1992). The nanoparticles were usually obtained by adding a solution of tripolyphosphate to a Ch solution in acetic acid. To study the interaction of $\mathrm{Ch}$ nanoparticles with ocular structures by spectrofluorimetry and confocal fluorescence microscopy, Ch was converted into a fluorescent derivative by the reaction between the fluorescein acid group and the $\mathrm{Ch}$ amino group. The stability of nanoparticles in the presence of proteins and enzymes was deemed a crucial issue. The presence of lysozyme was found not to significantly compromise the integrity of Ch nanoparticles since only a slight particle size reduction and no surface charge modification were observed (Lehr et al, 1992). Fluorescence microscopy of eyeball and lid sections confirmed the in vivo uptake of $\mathrm{Ch}$ nanoparticles by conjunctival and corneal epithelia. In vivo studies in rabbits showed that the nanoparticles were well tolerated by the ocular surface structures, which showed no histologic alterations nor abnormal inflammatory cells in cornea, conjunctiva and lids, in full consistency with the lack of clinical signs (de Salamanca et al., 2006).

Another potential colloidal drug carrier has been studied, which combines liposomes and $\mathrm{Ch}$ nanoparticles (Diebold et al. , 2007). The rehydration at $60^{\circ} \mathrm{C}$ of a lyophilized mixture of $\mathrm{Ch}$ nanoparticles, loaded with FITC-BSA, and liposomes led to the coating of nanoparticles 
with a phospholipid shell. The resulting nanosystem was characterized for size and zeta potential $(407.8 \pm 9.6 \mathrm{~nm}$ and $+5.8 \pm 1.3 \mathrm{mV}$ to $755.3 \pm 30.0 \mathrm{~nm}$ and $+14.7 \pm 0.4 \mathrm{mV}$, depending on composition) while its structure was assumed theoretically on the basis of an interaction between the positively charged nanoparticles and the negatively charged lipid vesicles, and a reorganization of the membranes to cover the nanoparticle surface. All nanosystems, namely, Ch nanoparticles, liposomes, and liposome-Ch nanoparticle complexes showed physical stability so far as no significant change in particle size was observed by photoncorrelation spectroscopy after $2 \mathrm{~h}$ in simulated lachrymal fluid. The underlying hypothesis of the authors was that an appropriate combination of liposomes and Ch nanoparticles could increase the ability of the resulting system to interact with biological surfaces and cell membranes and potentially deliver drugs to target tissues.

Studies of Ch-coated colloidal systems loaded with tetanus toxoid, indomethacin or diazepam, or Ch-based nanoparticles loaded with cyclosporin have been reviewed (Alonso \& Sanchez, 2009). It was concluded that a Ch coating could add a clear benefit to the potential of colloidal systems as ocular drug carriers, and that Ch nanoparticles might represent an interesting vehicle for drugs the target of which is the ocular mucosa.

The preparation of $\mathrm{Ch} / \mathrm{Cabopol}$ nanoparticles loaded with pilocarpine, a drug used for the treatment of glaucoma, has been reported (Huei-Jen et al., 2006). A solution of Ch in $1 \% \mathrm{w} / \mathrm{v}$ acetic acid was dropped into a Carbopol dispersion under stirring by a homogenizer to form an opalescent suspension of Ch/Carbopol nanoparticles. The pilocarpine-loaded nanoparticles were prepared by dissolving the drug in a measured volume of $\mathrm{Ch} / \mathrm{Carbopol}$ nanoparticle suspension and stirring for $48 \mathrm{~h}$. The drug-loaded nanoparticles were isolated by ultracentrifugation and dried by lyophilization. The nanoparticles were assumed to be formed by ionic interaction between the polycationic $\mathrm{Ch}$ and the polyanionic Carbopol. A particle size of $294 \pm 30 \mathrm{~nm}$, a zeta potential of $+55.78 \pm 3.41 \mathrm{mV}$ and a pilocarpine encapsulation efficiency of $77 \pm 4 \%$ were reported (Huei-Jen et al., 2006). After pilocarpine in various formulations, i.e., eye drops, liposomes, gel and nanoparticles, had been applied in the eyes of rabbits, the resulting miotic responses were compared. The decrease in pupil diameter was in the rank order of nanoparticles>liposomes>gel>eyedrops. With nanoparticles and liposomes the miosis effect lasted up to $24 \mathrm{~h}$. The AUC for the curve of decrease in pupil diameter vs. time was the largest for the nanoparticle formulation, indicating that this formulation was the most efficient system of the four tested for the topical delivery of pilocarpine (Huei-Jen et al., 2006).

Lipophilic nanoparticles for the delivery of the macrolide rapamycin for immunosuppression in corneal transplantation have recently been described ( $\mathrm{Xu}$-Bo et al., 2008). In brief, the preparation of rapamycin-loaded nanoparticles is described by the authors as follows. Poly(lactic acid) (PLA) and rapamycin, dissolved in acetone, are added under ultrasonication to an aqueous solution containing a Ch-cholesterol conjugate (ChChol), after which the solvent is removed by evaporation under stirring. The resulting nanoparticle suspension is centrifuged to remove the drug not entrapped within the particles, and then lyophilized. It is claimed that the amphiphilic Ch-Chol self-aggregates into nanoparticles, with hydrophobic microenvironment inside. When PLA was added to the aqueous $\mathrm{Ch}$-Chol under ultrasonication the size of the nanoparticles slightly increased to about $300 \mathrm{~nm}$, with a zeta potential of $+30.3 \mathrm{mV}$. The presence of PLA favoured the entrapment of the hydrophobic drug into the particles. The drug-loaded Ch-Chol/PLA nanoparticles and a rapamycin suspension were radiolabeled and the ocular distribution of 
either system was assessed by scintillation counter and single photon emission computed tomography (SPECT) image analysis. The rabbits treated with Ch-Chol/PLA nanoparticles showed radioactivity fractions remaining on cornea and conjunctiva significantly higher than those treated with the suspension of rapamycin. This behaviour is ascribed to the mucoadhesive character of the Ch nanoparticles (Xu-Bo et al., 2008), while disregarding the possibility of particle internalization by corneal and/or conjunctival cells. The radioactivity levels in the aqueous and iris/ciliary body were close to background level. This is taken as an indication that the corneal barrier hindered transport of either the drug or the nanoparticles. Nevertheless the prolonged residence of nanoparticles on the ocular surface is expected to promote drug absorption by the external ocular tissues. The rapamycin-loaded Ch-Chol/PLA were used to treat corneal allografts in comparison with the drug-free nanoparticles and the rapamycin suspension eyedrops. All of 10 grafts in the untreated control group were rejected within 13 days (median survival time, 10.6 \pm 1.26 days). Rabbits treated with empty nanoparticles rejected the corneal allografts in a median time of $10.9 \pm 1.45$ days and none of these grafts survived beyond 13 days. In the group treated with the rapamycin suspension, grafts were rejected between 19 and 27 days with a median survival time of $23.7 \pm 3.20$ days, while in the group treated with the rapamycin-loaded nanoparticles the median survival time of grafts was $27.2 \pm 1.03$ days and $50 \%$ grafts were still surviving by the end of the observation (4 weeks). These results indicated an improved immunosuppressive effect compared with rapamycin eye drops (Xu-Bo et al., 2008).

A very recent report describes the potential use in ocular drug delivery of liposomes coated with low molecular weight $(8 \mathrm{kDa}) \mathrm{Ch}$ (LCh) (Li et al., 2009). LCh was prepared by degradation of $\mathrm{Ch}$ with $\mathrm{H}_{2} \mathrm{O}_{2}$. Liposomes loaded with diclofenac sodium were coated with LCh (LChL). These systems, containing $0.1 \%$ diclofenac sodium, were compared with a $0.1 \%$ aqueous solution of the drug (control) for their effects on drug retention in precorneal area of rabbits. The LChL formulations produced significantly higher AUC (area under concentration in tear fluid vs. time curve) and longer MRT than either non-coated liposomes or the control solution, indicating that the LCh coating was essential to prolong the retention of liposome-encapsulated drug. No irritation or toxicity, caused by continual administration of LChL in a period of 7 days, resulted from an ocular tolerance study. The effect of LChL on drug corneal penetration was studied ( $\mathrm{Li}$ et al., 2009) using excised rabbit cornea and a diffusion apparatus (Camber, 1985). The apparent corneal permeability was determined by normalizing the permeant steady-state flux to the permeant concentration in the donor $(1.0$ $\mathrm{mg} / \mathrm{ml}$ ). The $\mathrm{P}_{\text {app }}$ produced by LChL was significantly higher than that relative to noncoated liposomes, while the latter was not higher than that produced by the aqueous solution. According to the authors (Li et al., 2009) the LCh coating could intensify liposome binding to the corneal surface, thus facilitating drug absorption into the cornea. In addition, the polycationic LCh could enhance the corneal permeability as in the case of the Ch of much higher molecular weight, described earlier (Di Colo et al., 2004b). These results are interesting in that they show that a $\mathrm{Ch}$ of as low a molecular weight as $8 \mathrm{kDa}$ can act as a corneal permeabilizer. However, the effect of this $\mathrm{Ch}$ on precorneal retention and corneal drug permeability is not reported for the case where drug and Ch are applied in solution, so the advantages of using a liposome formulation instead of a solution are not neatly highlighted by data.

\subsection{Xyloglucan}

Xyloglucan is a polysaccharide derived from tamarind seeds, therefore it is often coded TSP (tamarind seed polysaccharide). It has a backbone of $\beta(1 \rightarrow 4)$-linked glucose residues. Three 
out of four glucose units are substituted with $\alpha(1 \rightarrow 6)$ xylose residues, which are partially substituted by $\beta(1 \rightarrow 2)$-linked galactose, as shown in Fig.7. Some of the galactose residues can be further substituted with $\alpha(1 \rightarrow 2)$ fucose. TSP is highly water-soluble.

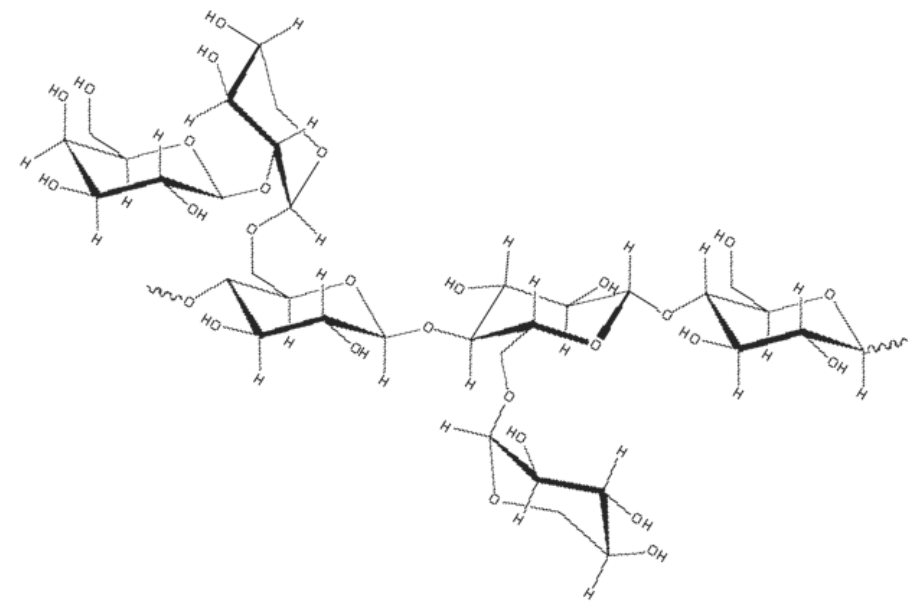

Fig. 7. Structure of the polysaccharide derived from tamarind seeds.

\subsubsection{Eye drops}

TSP has been described as a viscosity enhancer with mucomimetic activity. Therefore it is currently used in commercial artificial tears for the treatment of dry eye syndrome (DES) (Saettone et al., 1997). Concentrations of such antibiotics as gentamicin and ofloxacin in the rabbit aqueous humor depended on whether rabbit eyes were topically treated with antibiotics alone or drug formulations viscosified with TSP. In the latter instance significantly higher intraocular drug levels were observed. Also, the drugs delivered with TSP produced significantly higher intra-corneal levels than those attained with the corresponding TSP-free formulations. This suggested that TSP enhances corneal drug accumulation by reducing the wash-out of drugs (Ghelardi et al., 2000).

Eye drops containing $3 \mathrm{mg} / \mathrm{ml}$ rufloxacin and $10 \mathrm{mg} / \mathrm{ml} \mathrm{TSP}$, along with other excipients were topically applied to rabbits for the treatment of experimental Pseudomonas aeruginosa and Staphylococcus aureus keratitis. Rufloxacin delivered by the polysaccharide reduced $P$. aeruginosa and $S$. aureus in the cornea at a higher rate than that obtained with rufloxacin alone. These results suggested that TSP is able to prolong the precorneal residence time of the antibiotic and enhance drug accumulation in the cornea, thereby increasing the intraaqueous antibiotic penetration. (Ghelardi et al., 2004).

\subsubsection{In situ-gelling systems}

When xyloglucan is partially degraded by $\beta$-galactosidase the resultant product exhibits thermally reversible gelation in dilute aqueous solutions, which does not occur with native xyloglucan. Gelation is only possible when the galactose removal exceeds $35 \%$. The sol-gel 
transition temperature was shown to decrease from 40 to $5{ }^{\circ} \mathrm{C}$ when the galactose removal ratio increased from 35 to $58 \%$ (Nanjawade et al., 2007). Xyloglucan formulations have been studied for ocular delivery of pilocarpine, using Poloxamer 407 as a positive thermosensitive control. The $1.5 \mathrm{wt}$ \% xyloglucan formulation enhanced the miotic response to a degree similar to a 25 wt.\% Poloxamer 407 gel (Nanjawade et al., 2007).

\subsection{Arabinogalactan}

Arabinogalactan (AG), a natural polysaccharide contained in Larix Occidentalis (Western Larch), has been found to be biocompatible in the eye, mucomimetic and mucoadhesive (Burgalassi et al., 2007). It is a non-ionic highly branched polysaccharide of the 3,6- $\beta-\mathrm{D}$ galactan type, the side chains of which consist of $\beta$-galactose and $\beta$ arabinose residues (Gregory \& Kelly, 1999).

\subsubsection{Eye drops}

AG dispersions showed a Newtonian non-viscous behaviour $(\eta=1.6 \mathrm{mPas}$ at $10 \% \mathrm{w} / \mathrm{w}$ concentration) along with good mucoadhesive properties, useful for retention on the eye surface. In fact, a prolonged time of residence in rabbit eyes was ascertained using fluorescein-labeled AG. Five percent w/w AG exerted a good protective effect against the appearance of corneal dry spots. It also reduced significantly the healing time of an experimental corneal lesion. These findings suggested that AG is potentially effective for dry eye protection and in the treatment of corneal wounds (Burgalassi et al., 2007).

\subsection{Cellulose derivatives}

Cellulose is a polysaccharide consisting of a linear chain of several hundred to over ten thousand $\beta(1 \rightarrow 4)$ linked D-glucose units. The chemical structures of cellulose derivatives used in topical ocular formulations (methyl cellulose, hydroxyethyl cellulose, hydroxypropylmethyl cellulose, sodium carboxymethyl cellulose) are shown in Fig.8.

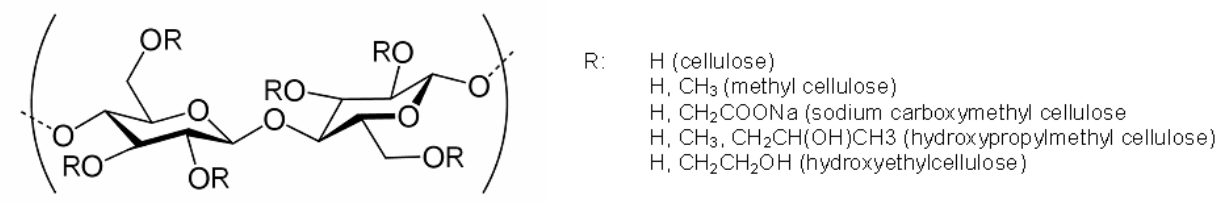

Fig. 8. Structure of cellulose and its derivatives.

\subsubsection{Eye drops}

Eye drops containing cellulose derivatives, such as methyl cellulose (MC), hydroxypropylmethyl cellulose (HPMC) or sodium carboxymethyl cellulose (NaCMC), have largely been used as eye lubricants for the treatment of DES. This is characterized by a set of alterations of the eye surface which could relate to tear quality, normal makeup of tear film and alterations in blinking or regular closing of eyelids which entail a reduction of the stability of the tear film and the alteration of the eye surface. HPMC solutions were patented as a semisynthetic substitute for tear-film (Hahnenberger, 1997). When applied, an HPMC solution acts to absorb water, thereby expanding the thickness of the tear film and resulting in extended time of lubricant presence on the cornea and decreased eye irritation (Koroloff 
et al., 2004). Aside from its widespread commercial and retail availability in a variety of products, HPMC has been used as a $2 \%$ solution during surgery to aid in corneal protection and during orbital surgery. Treatment with an isotonic $0.5 \%$ solution of $\mathrm{NaCMC}$ found in the market (Cellufresh ${ }^{\circledR}$, Allergan SA, Madrid) produced a significant decrease in the frequency of subjective DES symptoms and improvement of tear film interface stability and corneal surface wettability compared to controls (Bruix et al., 2006).

Hydroxyethyl cellulose (HEC) is used as a viscosity-enhancing agent in ophthalmic formulations to prolong corneal contact time and increase intraocular drug levels.

\subsubsection{In situ-gelling systems}

Aqueous solutions of MC or HPMC at concentrations in the 1-10 wt.\% range are liquid at low temperatures, but form gels upon heating. The transition temperature is between 40 and $50{ }^{\circ} \mathrm{C}$ for $\mathrm{MC}$ and between 75 and $90^{\circ} \mathrm{C}$ for HPMC. Sodium chloride lowers the sol-gel transition temperature of $\mathrm{MC}$ to $32-34^{\circ} \mathrm{C}$, while the transition temperature of HPMC can be lowered to about $40^{\circ} \mathrm{C}$ by reducing the hydroxypropyl molar substitution (Nanjawade et al., 2007).

Gelation of MC or HPMC solutions is produced by the hydrophobic interaction between methoxy-substituted residues. At low temperatures the macromolecules are hydrated and interact by simple entanglement. At higher temperatures the hydration of polymer chains tends to decrease, chain-chain associations take place, and the system approaches a network structure, corresponding to a sharp rise in viscosity. This sol-gel transition has been exploited to design in situ gelling systems having low viscosity at $23{ }^{\circ} \mathrm{C}$ and forming soft gels at $37^{\circ} \mathrm{C}$ (Nanjawade et al., 2007).

\subsection{Hyaluronic acid}

Hyaluronic acid (HA) is a high molecular weight, natural and linear polysaccharide composed of $\beta-1,3-\mathrm{N}$-acetyl glucosamine and $\beta-1,4$-glucuronic acid repeating disaccharide units (Fig.9). This biocompatible, nonimmunogenic and biodegradable polymer is one of the most hygroscopic molecules in nature, in fact, HA can hydrate up to 1000 times its dry weight. This property is responsible for enhanced hydration of the corneal surface. Moreover, ocular topical application of formulations based on hyaluronic acid reduces the elimination rate of tear fluid and stabilizes the tear film. This is useful for the treatment of DES (Guillaumie et al., 2010).

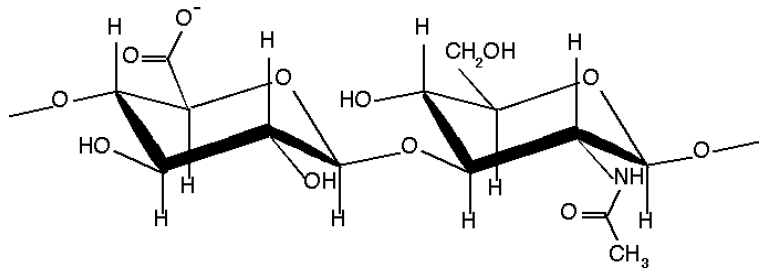

Fig. 9. Structure of hyaluronic acid.

\subsubsection{Eye drops}

Non-Newtonian and shear thinning properties grant HA solutions a high viscosity at low shear rate (when the eye is open) and a low viscosity at high shear rate (during blinking) thus allowing an even distribution of the solution, improving lubrication of the ocular 
surface, retarding drainage, improving bioavailability, and reducing discomfort. Another important feature of this high molecular weight, anionic biopolymer is its mucoadhesivity, which provides effective coating and long-lasting protection of the cornea as well as extended residence times on the ocular surface (Guillaumie et al., 2010). Finally, when topically instilled on the eye, hyaluronic acid has been shown to promote physiological wound healing by stimulating corneal epithelial migration and proliferation of keratocytes and to reduce the healing time of corneal epithelium. Topical ophthalmic solutions should exhibit a certain degree of viscosity to prevent immediate drainage from the ocular surface and provide there high efficacy and long residence time. However, the solutions should not be too viscous to avoid blurred vision and to ease their manufacturing process including their sterile filtration (Guillaumie et al., 2010).

\subsection{Alginic acid/sodium alginate}

Alginic acid (AA) is a natural hydrophilic polysaccharide distributed widely in the cell walls of brown algae. It contains the monomers $\beta$-D-mannuronic acid $(\mathrm{M})$ and $\alpha$-Lguluronic acid $(\mathrm{G})$, arranged as homopolymeric blocks of M-M blocks or G-G blocks together with blocks of alternating sequence (M-G). The polymer forms 3-dimensional ionotropic hydrogel matrices, generally by the preferential interaction of calcium ions with the $G$ moieties resulting in the formation of inhomogeneous gels (Grant et al., 1973 via Cohen et al., 1997).

\subsubsection{In situ-gelling systems}

An aqueous solution of sodium alginate (NaAA) can gel in the eye. Alginates with G contents of more than $65 \%$ instantaneously formed gels upon addition to simulated tear fluid, due to ionotropic gelation by $\mathrm{Ca}^{++}$ions. In contrast, alginates having low $\mathrm{G}$ contents formed weak gels at a comparatively low rate (Cohen et al., 1997). Pilocarpine was released slowly from alginate gels in vitro over a period of $24 \mathrm{~h}$, and the release occurred mostly via diffusion from the gels. In agreement with the in vitro results, intraocular pressure (IOP) measurements of rabbit eyes treated with $2 \% \mathrm{w} / \mathrm{v}$ pilocarpine nitrate in solution or in the in situ gel-forming formulation containing high G-content NaAA indicated that the latter significantly extended the duration of the IOP-reducing effect compared to the former $(10 \mathrm{~h}$ vs. $3 \mathrm{~h}$ ). On the other hand, the effect of low G-content NaAA on the duration and extent of IOP reduction was insignificant (Cohen et al., 1997).

AA has been evaluated as a potential vehicle in ophthalmic in situ-gelling solutions for prolonging the IOP-reducing effect of carteolol. In vitro studies indicated that carteolol is released slowly from mucoadhesive AA formulations, suggesting an ionic interaction between the basic drug and AA. IOP measurements of rabbit eyes treated with a $1 \%$ carteolol formulation with or without AA showed that this polymer significantly extended the duration of the IOP-reducing effect to $8 \mathrm{~h}$. AA produced an ocular bioavailability increase of a carteolol formulation, as indicated by a drug concentration in the target tissue, following a once-daily administration, equivalent to a twice-daily administration of the AAfree carteolol solution (Sechoy et al., 2000).

\subsection{Gellan gum}

Gellan gum (GG), commercial name Gelrite ${ }^{\circledR}$, is a water-soluble polysaccharide produced by the bacterium Pseudomonas elodea. The repeating unit of the polymer is a tetrasaccharide 
consisting of two residues of D-glucose and one of each L-rhamnose and D-glucuronic acid, in the following sequence: [D-Glc $(\beta 1 \rightarrow 4) \mathrm{D}-\mathrm{GlcA}(\beta 1 \rightarrow 4) \mathrm{D}-\mathrm{Glc}(\beta 1 \rightarrow 4) \mathrm{L}-\mathrm{Rha}(\alpha 1 \rightarrow 3)]_{\mathrm{n}}$.

\subsubsection{In situ-gelling systems}

GG solutions form gels in the presence of mono- or divalent cations, therefore a $0.6 \%$ GG solution containing $0.34 \%$ timolol maleate underwent a sol-gel transition in the rabbit eye due to the presence of sodium and calcium ions in tear fluid. In vitro release of timolol from GG gelled solutions was retarded and controlled by drug diffusion in the gel. Accordingly, in vivo the formation of the gel prolonged the precorneal residence time, and therefore, it increased the ocular bioavailability of timolol in the cornea, aqueous humor and iris+ciliary body of rabbits (Rozier et al., 1989). A similar in situ-gelling behaviour and in vitro release of the antibacterial agent pefloxacin was reported of a $0.6 \%$ GG solution. This allowed attainment of the minimum inhibitory concentration of antibacterial in the aqueous of rabbits, and maintained it for $12 \mathrm{~h}$, while with the conventional eye drops the drug concentration in the aqueous after the same time interval dropped to negligible values (Sultana et al., 2006).

\subsection{Polysaccharide mixtures}

Mixtures of polysaccharides have been investigated considering that possible interpolimer non-covalent interaction might generate excipients for eye drops, having synergistically improved properties over those of the separate polymers. Ascertaining the above possibility and evaluating the composition of the mixture corresponding to the strongest interaction and optimal biopharmaceutical properties have been the fundamental purposes of these studies.

\subsubsection{Eye drops}

An interaction between TSP and HA in aqueous solution was ascertained. Various TSP/HA mixtures were studied, among which the $3 / 2$ ratio showed the strongest interaction. The properties of this mixture as a potential excipient for eye drops were synergistically improved over those of the separate polymers. Information about the nature of interpolymer interactions and their dependence on TSP/HA ratio was obtained by nuclear magnetic resonance (NMR) spectroscopy. The affinity of the TSP/HA (3/2) mixture for mucin, assessed by NMR, is higher than that of the single polysaccharides. The mucoadhesivity of this mixture, evaluated in vitro by NMR or viscometry, and in vivo by its mean and maximum residence time in rabbit precorneal area, is stronger than that of the component polysaccharides or the TSP/HA mixtures of different composition. TSP/HA (3/2) is little viscous and well tolerated by rabbit eyes, so it shows a considerable potential for the treatment of DES. This mixture stabilizes the tear film, hence it has been shown to prolong the residence of drugs, such as ketotifen fumarate and diclofenac sodium, in tear fluid. It is unable to permeabilize the cornea, therefore mucoadhesivity is responsible for the TSP/HA (3/2) synergistic enhancement of either extra- or intra-ocular drug bioavailability (UccelloBarretta et al., 2010).

\subsubsection{In situ-gelling systems}

The rheological properties of GG, NaAA and GG/NaAA solutions were evaluated. It was found that the optimum concentration of GG solution for in situ gel-forming delivery 
systems was $0.3 \% \mathrm{w} / \mathrm{w}$ and that of NaAA solution was $1.4 \% \mathrm{w} / \mathrm{w}$. The mixture of $0.2 \% \mathrm{GG}$ and $0.6 \% \mathrm{NaAA}$, when gelled by simulated tear fluid, showed a significant enhancement in gel strength in physiological conditions. Such a gelled mixture released in vitro the anticancer drug matrine most slowly. When the solution of this mixture was instilled in rabbit eyes the in situ gelling significantly prolonged drug residence in the precorneal area over the time allowed by the GG or NaAA solution alone (Liu et al., 2010).

A further in situ gel-forming polysaccharide mixture is composed of $\mathrm{Ch}$ and GG. Both polysaccharides form gels in the physiological conditions of the eye, gelation of $\mathrm{Ch}$ being activated by the neutral $\mathrm{pH}$ of tear fluid, that of GG by the cations of the electrolytes contained in such a fluid. The in situ-gelling system composed of $0.25 \% \mathrm{w} / \mathrm{v} \mathrm{Ch}$ and $0.50 \%$ w/v GG was prepared by mixing solutions of Ch and GG in acetate buffer $\mathrm{pH}$ 5.5-6.0 and ultrapure water, respectively. The system was medicated with $0.25 \% \mathrm{w} / \mathrm{v}$ timolol maleate. In vitro transcorneal permeation studies on the formulation showed a significant increase of the drug amount permeated across goat cornea in $4 \mathrm{~h}$ compared to plain drug solution and the in situ-gelling system based on GG alone. This effect was ascribed to the permeationenhancing ability of $\mathrm{Ch}$. In vivo precorneal drainage of the formulation was studied in rabbits by gamma scintigraphy. Radio-labelled timolol maleate applied as plain solution cleared very rapidly from the corneal region, whereas the drug applied by the Ch/GG in situ-gel forming formulation was retained on the corneal surface for a remarkably longer time (Gupta et al., 2010).

\subsection{Comparison of polysaccharide mucoadhesivity}

Different polysaccharides, i.e., AG, TSP, HA, HEC, have been compared for their ability to resist removal from tear fluid. Their mucoadhesivity was compared in vitro, by the polymerinduced viscosity increase of a mucin dispersion, and in vivo, by the polymer residence time in rabbit tear fluid (Di Colo et al., 2009).

The optimal polymer to be used as an additive in ophthalmic drops should be mucoadhesive without increasing the viscosity of the solution to an excessive extent. A solution of TSP $0.7 \% \mathrm{w} / \mathrm{v}$ was shown to possess more of these properties than the other polymers at comparison, in fact, it exhibited the highest MRT in the rabbit precorneal area. HA and HEC, although mucoadhesive, increased the solution viscosity to an excessive degree, and this, in addition to worsening the patient compliance, could induce an anomalous reflex tearing with consequent acceleration of precorneal clearance. AG, at the concentrations at which TSP, HA and HEC were tested, exhibited no significant mucoadhesive properties. This polysaccharide, nevertheless, did not increase the solution viscosity, so it showed the potential for being used at much higher concentrations, e.g., 5$10 \% \mathrm{w} / \mathrm{w}$, at which its mucoadhesivity is significant (Burgalassi et al., 2007). In virtue of its mucoadhesivity, TSP $0.7 \% \mathrm{w} / \mathrm{v}$ is supposed to stabilize the tear film. For this reason the residence of two different drugs, i.e., ketotifen fumarate and diclofenac sodium, in the precorneal area of rabbit eyes was significantly prolonged by this excipient (Di Colo et al., 2009).

\section{Conclusion}

The polysaccharides, either natural or semi-synthetic, described in the present survey are non-irritant to the eye and show an ample array of possible solutions to formulation issues 
in ophthalmology. The polysaccharides introduced in eye drops are mucoadhesive and mucomimetic at comparatively low viscosities. Hence they have been used as lubricants of the eye surface to treat DES. In virtue of their mucoadhesivity they stabilize the tear film and prolong the residence of ophthalmic drugs on the eye surface thereby increasing their extraand intra-ocular bioavailability. $\mathrm{Ch}$ and some of its polycationic derivatives, when topically applied via eye drops, have shown the additional ability to promote intra-ocular drug absorption by reversibly permeabilizing the cornea. It is in virtue of this peculiar ability and of mucoadhesivity that $\mathrm{Ch}$ has been used to prepare nanoparticles for ocular topical application, or added to ophthalmic in situ-gelling systems, based on PEO, poloxamer, or PNIPAAm, intended to improve the ocular drug bioavailability. When the basic excipients of in situ-gelling systems were polysaccharides, such as AA/NaAA or GG, the basic principles of the drug bioavailability increase were the prolonged retention of gel in precorneal area and the slow drug release from gel.

Most of the in vivo studies of ocular formulations employing polysaccharides have used rabbits as the animal model. It must be recognized, however, that the precorneal clearance determined in rabbits is not representative of that in humans, mainly due to differences in blinking frequency. Such differences may be reflected in differences in shear-thinning of tear film, mucoadhesion of polymer and ultimately in drainage of drugs. Nevertheless, the inaccuracies due to blinking differences can be considered to be similar for the different preparations tested, then the rabbit model is deemed robust for those studies where it has been used for comparative purposes.

\section{Abbreviation}

$\begin{array}{ll}\text { AA } & \begin{array}{l}\text { alginic acid } \\ \text { arabinogalactan } \\ \text { area under curve } \\ \text { chitosan } \\ \text { AUC }\end{array} \\ \text { chitosan-cholesterol conjugate } \\ \text { Ch-Chol } & \text { chitosan hydrochloride } \\ \text { Ch-HCl } & \text {-carboxymethyl chitosan } \\ \text { CMCh } & \text { 2-diethylaminoethyl chloride } \\ \text { DEAE-Cl } & \text { dry eye syndrome } \\ \text { DES } & \text { degree of substitution } \\ \text { DS } & \text { enhancement ratio } \\ \text { ER } & \text { fluorescein-isothiocyanate } \\ \text { FITC } & \text { guluronic acid unit in AA } \\ \text { G } & \text { gellan gum } \\ \text { GG } & \text { hyaluronic acid } \\ \text { HA } & \text { hydroxyethyl cellulose } \\ \text { HEC } & \text { hydroxypropylmethyl cellulose } \\ \text { HPMC } & \text { intra ocular pressure } \\ \text { IOP } & \text { low molecular weight chitosan } \\ \text { LCh } & \text { liposomes coated with LCh } \\ \text { LChL } & \text { mannuronic acid unit in AA } \\ \text { M } & \text { methyl cellulose } \\ \text { MC } & N \text { - methyl-diethylaminoethyl dextran } \\ \text { MeDEAED } & \end{array}$




\begin{tabular}{|c|c|}
\hline $\begin{array}{l}\text { MRT } \\
n\end{array}$ & $\begin{array}{l}\text { mean precorneal retention time } \\
\text { mean number of quaternary ammonium groups in the pendant } \\
\text { chains of } \mathrm{N}^{+} \text {-Ch }\end{array}$ \\
\hline NaAA & sodium alginate \\
\hline $\mathrm{NaCMC}$ & sodium carboxymethyl cellulose \\
\hline $\mathrm{N}^{+}-\mathrm{Ch}$ & $\begin{array}{l}\mathrm{N}, \mathrm{O}-[\mathrm{N}, \mathrm{N} \text {-diethylaminomethyl(diethyldimethylene } \\
\text { ammonium }{ }_{n} \text { methyl] chitosan }\end{array}$ \\
\hline $\mathrm{N}^{+}-\mathrm{Ch}-\mathrm{SH}$ & thiolated quaternary ammonium-chitosan conjugate \\
\hline $\mathrm{P}_{\mathrm{app}}$ & apparent permeability \\
\hline PEO & poly(ethylene oxide) \\
\hline PLA & poly(lactic acid) \\
\hline PNIPAAm & poly( $N$-isopropylacrylamide) \\
\hline PVA & poly(vinyl alcohol) \\
\hline QD & quaternization degree \\
\hline RRCE & rabbit reconstituted corneal epithelium \\
\hline SPECT & single photon emission computed tomography \\
\hline TMC & $N$-trimethyl chitosan \\
\hline TMCL & TMC synthesized from a Ch of MW $580 \mathrm{kDa}$ \\
\hline $\mathrm{TMCH}$ & TMC synthesized from a Ch of MW $1460 \mathrm{kDa}$ \\
\hline TSP & tamarind seed polysaccharide \\
\hline
\end{tabular}

\section{References}

Alonso, M. J. \& Sánchez, A. (2009). The potential of chitosan in ocular drug delivery. J. Pharm. Pharmacol., Vol. 55, pp. 1451-1463.

Artursson, P.; Lindmark, T.; Davis, S.S. \& Illum, L. (1994). Effect of chitosan on the permeability of monolayers of intestinal epithelial cells (Caco-2). Pharm. Res., Vol. 11, pp. 1358-1361.

Bruix, A; Adan, A. \& Casaroli-Marano, R.P. (2006). Efficacy of sodium carboxymethylcellulose in the treatment of dry eye syndrome. Arch. Soc. Esp. Oftalmol., Vol. 81, pp. 85-92.

Burgalassi, S.; Nicosia, N.; Monti, D.; Falcone, G.; Boldrini, E. \& Chetoni, P. (2007). Larch arabinogalactan for dry eye protection and treatment of corneal lesions: Investigation on rabbits. J. Ocul Pharmacol. Ther., Vol. 23, pp. 541-549.

Camber, O. (1985). An in vitro model for determination of drug permeability through the cornea. Acta Pharm. Suec., Vol. 22, pp. 335-342.

Cao, Y.; Zhang, C.; Shen, W.; Cheng, Z.; Yu, L.L. \& Ping, Q. (2007). Poly(Nisopropylacrylamide) — chitosan as thermosensitive in situ gel-forming system for ocular drug delivery. J.Control. Rel., Vol. 120, pp. 186-194.

Chan, V.; Mao, H.Q. \& Leong, K.W. (2001). Chitosan-induced perturbation of dipalmitoylsn-glycero-3-phosphocholine membrane bilayer. Langmuir, Vol. 44, pp. 201-208.

Cohen, S.; Lobel, E.; Trevgoda, A.; Peled, Y. (1997). A novel in situ-forming ophthalmic drug delivery system from alginates undergoing gelation in the eye. J. Control. Rel.; Vol. 44, pp. 201-208.

de Salamanca, A.E.; Diebold, Y.; Calonge, M.; García-Vazquez, C.; Callejo S.; Vila, A. \& Alonso, M.J. (2006). Chitosan nanoparticles as a potential drug delivery system for 
the ocular surface: toxicity, uptake mechanism and in vivo tolerance. Invest. Ophthalmol. Vis. Sci., Vol. 47, pp. 1416-1425.

Diebold, Y.; Jarrín, M.; Sáez, V.; Carvalho, E.L.S.; Orea, M.; Calonge, M.; Seijo, B. \& Alonso, M. J. (2007). Ocular drug delivery by liposome-chitosan nanoparticle complexes (LCS-NP). Biomaterials, Vol. 28, pp. 1553-1564.

Di Colo, G.; Burgalassi, S.; Chetoni, P.; Fiaschi, M.P.; Zambito, Y. \& Saettone, M.F. (2001a). Gel-forming erodible inserts for ocular controlled delivery of ofloxacin. Int. J. Pharm., Vol. 215, pp. 101-111.

Di Colo, G.; Burgalassi, S.; Chetoni, P.; Fiaschi, M. P.; Zambito, Y. \& Saettone, M.F. (2001b). Relevance of polymer molecular weight to the in vitro/in vivo performances of ocular inserts based on poly(ethylene oxide). Int. J. Pharm., Vol. 220, pp. 169-177.

Di Colo, G.; Zambito, Y.; Burgalassi, S.; Serafini, A. \& Saettone, M.F. (2002). Effect of chitosan on in vitro release and ocular delivery of ofloxacin from erodible inserts based on poly(ethylene oxide). Int. J. Pharm., Vol. 248, pp. 115-122.

Di Colo, G.; Burgalassi, S.; Zambito, Y.; Monti, D. \& Chetoni, P. (2004a). Effects of different $\mathrm{N}$-trimethylchitosans on in vitro/in vivo ofloxacin transcorneal permeation. J. Pharm. Sci., Vol. 93, pp. 2851-2862.

Di Colo, G.; Zambito, Y.; Burgalassi, S.; Nardini, I. \& Saettone, M.F. (2004b). Effect of chitosan and of $\mathrm{N}$-carboximethylchitosan on intraocular penetration of topically applied ofloxacin. Int. J. Pharm., Vol. 273, pp. 37-44.

Di Colo, G.; Zambito, Y. \& Zaino, C. (2008). Polymeric enhancers of mucosal epithelia permeability: synthesis, transepithelial penetration-enhancing properties, mechanism of action, safety issues. J. Pharm. Sci., Vol. 97, pp. 1652-1680.

Di Colo, G.; Zambito, Y.; Zaino, C. \& Sansò, M. (2009). Selected polysaccharides at comparison for their mucoadhesiveness and effect on precorneal residence of different drugs in the rabbit model. Drug Dev. Ind. Pharm., Vol. 35, pp. 941-949.

Dodane, V. \& Vilivalam, V.D. (1998). Pharmaceutical applications of chitosan. Pharma Sci. Technol. Today, Vol. 1, pp. 246-253.

Fang, N.; Chan, V.; Mao, H. Q. \& Leong, K. W. (2001). Interactions of phospholipid bilayer with chitosan: effect of molecular weight and $\mathrm{pH}$. Biomacromolecules, Vol. 2, pp. 1161-1168.

Felt, O.; Buri, P. \& Gurny, R. (1998). Chitosan: a unique polysaccharide for drug delivery. Drug Dev. Ind. Pharm., Vol. 24, pp. 979-993.

Ghelardi, E.; Tavanti, A.; Pelandroni, F.; Lupetti, A.; Blandizzi, C.; Boldrini, E.; Campa, M. \& Senesi M. (2000). Effect of a novel mucoadhesive polysaccharide obtained from tamarind seeds on the intraocular penetration of gentamicin and ofloxacin in rabbits. J. Antimicrob. Chemother., Vol. 48, pp. 3396-3401.

Ghelardi, E.; Tavanti, A.; Davini, P.; Pelandroni, F.; Solvetti, S.; Parisio, E.; Boldrini, E.; Senesi, S. \& Campa, M. (2004). A mucoadhesive polymer extracted from tamarind seed improves the intraocular penetration and efficacy of rufloxacin in topical treatment of experimental bacterial keratitis. Antimicrob. Agents Chemother., Vol. 48, pp. 3396-3401.

Grant, G.T.; Morris, E.R.; Rees, D.A.; Smith, P.J.C. \& Thom, D. (1973). Biological interactions between polysaccharides and divalent cations: The egg box model. FEBS Lett., Vol. 32, pp. 195-198. 
Gregory, S. \& Kelly, N.D. (1999). Larch arabinogalactan: Clinical relevance of a novel immune-enhancing polysaccharide. Altern. Med. Rev., Vol. 4, pp. 96-103.

Guillaumie, F.; Furrer, P.; Felt-Baeyens, O.; Fuhlendorff, B.L.; Nymand, S.; Westh, P.; Gurny, R. \& Schwach-Abdellaoui, K. (2010). Comparative studies of various hyaluronic acids produced by microbial fermentation for potential topical ophthalmic applications. J. Biomed. Mater. Res. Part A, Vol. 92, No. 4, pp. 1421-1430.

Gupta, H.; Jain, S.; Mathur, R.; Mishra, P. \& Mishra, A. K. (2007). Sustained ocular drug delivery from a temperature and $\mathrm{pH}$ triggered in situ gel system. Drug Deliv., Vol. 14, pp. 507-515.

Gupta, H.; Velpandian, T. \& Jain, S. (2010). Ion- and pH-activated novel in-situ gel system for sustained ocular drug delivery. J. Drug Targeting, Vol. 18, pp. 499-505.

Hahnenberger, R.W. (1997). Pharmaceutical composition containing carbachol and other cholinergic substances. United States Patent 5,679,713.

Hamman, J.H.; Schultz, C. M. \& Kotzé, A.F. (2003). N-trimethyl chitosan chloride: optimum degree of quaternization for drug absorption enhancement across epithelial cells. Drug Dev. Ind. Pharm., Vol. 29, pp. 161-172.

Huei-Jen, K.; Hong-Ru, L.; Yu-Li, L. \& Shi-Ping Y. (2006). Characterization of pilocarpineloaded chitosan/Carbopol nanoparticles. J. Pharm. Pharmacol., Vol. 58, pp. 79-186.

Hui H.W. \& Robinson, J. R.(1985). Ocular drug delivery of progesterone using a bioadhesive polymer. Int. J. Pharm., Vol. 26,pp. 203-213.

Illum, L. (1998). Chitosan and its use as a pharmaceutical excipient. Pharm. Res., Vol. 15, pp. 1326-1331.

Illum, L.; Farraj, N. F. \& Davis, S.S. (1994). Chitosan as a novel nasal delivery system for peptide drugs. Pharm. Res., Vol. 11, pp. 1186-1189.

Janes, K.A.; Calvo, P. \& Alonso, M.J. (2001). Polysaccharide colloidal particles as delivery systems for macromolecules. Adv. Drug Deliv. Rev., Vol. 47, pp. 83-97.

Koroloff, N.; Boots, R.; Lipman, J.; Thomas, P.; Rickard, C. \& Coyer, F. (2004). A randomised controlled study of the efficacy of hypromellose and Lacri-Lube combination versus polyethylene/Cling wrap to prevent corneal epithelial breakdown in the semiconscious intensive care patien". Intensive Care Med, Vol. 30, No. 6, pp. 11221126.

Kotzé, A.F.; Lueßen, H.L.; De Leeuw, B.J.; De Boer, A.G.; Verhoef, J.C. \& Junginger, H.E. (1997). N-trimethyl chitosan chloride as a potential absorption enhancer across mucosal surfaces: in vitro evaluation in intestinal epithelial cells (Caco-2). Pharm. Res., Vol. 14, pp. 1197-1202.

Kotzé, A.F.; Lueßen, H.L.; De Leeuw, B.J.; De Boer, A.G.; Verhoef, J.C. \& Junginger, H.E. (1998). Comparison of the effect of different chitosan salts and N-trimethyl chitosan chloride on the permeability of intestinal epithelial cells (Caco-2). J. Control. Rel., Vol. 51, pp. 35-46.

Lee, V.H.L. \& Robinson, J.R. (1986). Review: topical ocular drug delivery: recent developments and future challenges. J. Ocul. Pharmacol., Vol. 2, pp. 67-108.

Lehr, C.M.; Bowstra, J.A.; Schacht, E.H. \& Junginger, H.E. (1992). In vitro evaluation of mucoadhesive properties of chitosan and some other natural polymers. Int. J. Pharm., Vol. 78, pp. 43-48. 
Li, N.; Zhuang, C.; Wang, M.; Sun, X.; Nie, S. \& Pan, W. (2009). Liposome coated with low molecular weight chitosan and its potential use in ocular drug delivery. Int. J. Pharm., Vol. 379, pp. 131-138.

Liu, Y.; Liu, J.; Zhang, X.; Huang, Y. \& Wu, C. (2010). In situ gelling gelrite/alginate formulations as vehicles for ophthalmic drug delivery. AAPS Pharm. Sci. Technol., Vol. 11, pp. 610-620.

Ludwig, A. (2005). The use of mucoadhesive polymers in ocular drug delivery. Adv. Drug Del. Rev., Vol. 57, pp. 1595-1639.

Macha, S. \& Mitra, A. K. (2001). Ocular pharmacokinetics of cephalosporins using microdialysis. J. Ocular Pharmacol. Ther., Vol. 17, pp. 485-498.

Maeda, T.; Kanda, T.; Yonekura, Y.; Yamamoto, K. \& Aoyagi, T. (2006). Hydroxylated poly( $N$-isopropylacrylamide) as functional thermoresponsive materials. Biomacromolecules, Vol. 7, pp. 545-549.

Majumdar, S.; Hippalgaonkar, K. \& Repka, M.A. (2008). Effect of chitosan, benzalkonium chloride and ethylenediaminotetraacetic acid on permeation of acyclovir across isolated rabbit cornea. Int. J. Pharm., Vol. 348, pp. 175-178.

Muzzarelli, R.A.A.; Tanfani, F.; Emmanueli, M. \& Mariotti, S. (1982). N(carboxymethylidene)-chitosans and $\mathrm{N}$-(carboxymethyl)-chitosans: novel chelating polyampholytes obtained from chitosan glyoxylate. Carbohydr. Res., Vol. 107, pp. 199-214.

Nagarwal, R. C.; Kant, S.; Singh, P.N.; Maiti, P. \& Pandit, J.K. (2009). Polymeric nanoparticulate system: A potential approach for ocular drug delivery. J. Control. Rel., Vol. 136, pp. 2-13.

Nanjawade, B.V.; Manvi, F.V. \& Manjappa, A.S. (2007). In situ-forming hydrogels for sustained ophthalmic drug delivery. J. Control. Rel., Vol. 122, pp. 119-134.

Paul, W. \& Sharma, C. (2000). Chitosan, a drug carrier for the $21^{\text {st }}$ century. STP Pharma Sci., Vol. 10, pp. 5-22.

Rittenhouse, K.D.; Peiffer, R.L. Jr. \& Pollack, G.M. (1999). Microdialysis evaluation of the ocular pharmacokinetics of propanolol in the conscious rabbit. Pharm. Res., Vol. 16, pp. 736-742.

Rittenhouse, K.D. \& Pollack, G.M. (2000). Microdialysis and drug delivery to the eye. Adv. Drug Deliv. Rev., Vol. 45, pp. 229-241.

Rozier, A.; Mazuel, C.; Grove, J. \& Plazonnet, B. (1989). Gelrite ${ }^{\circledR}$ : A novel, ion-activated, insitu gelling polymer for ophthalmic vehicles. Effect on bioavailability of timolol. Int. J. Pharm., Vol. 57, pp. 163-168

Saettone, M. F. \& Salminen, L. (1995). Ocular Inserts for topical delivery. Adv. Drug Deliv. Rev., Vol. 16, pp. 95-106.

Saettone, M.F.; Burgalassi, S.; Boldrini, E.; Bianchini, P. \& Luciani, G. (1997). Ophthalmic solutions viscosified with tamarind seed polysaccharide. International patent application. PCT/IT97/00026.

Sechoy, O.; Tissie, G.; Sebastian, C.; Maurin, F.; Driot, J.Y. \& Trinquand, C. (2000). A new long acting ophthalmic formulation of carteolol containing alginic acid. Int. J. Pharm., Vol. 207, pp. 109-116.

Singla, A. K. \& Chawla, M. (2001). Chitosan: some pharmaceutical and biological aspects an update. J. Pharm. Pharmacol., Vol. 53, pp. 1047-1067. 
Snyman, D.; Hamman, J.H.; Kotzé, J.S.; Rollings, J.E. \& Kotzé, A.F. (2002). The relationship between the absolute molecular weight and the degree of quaternisation of $\mathrm{N}$ trimethyl chitosan chloride. Carbohydrate Polym., Vol. 50, pp. 145-150.

Snyman, D.; Hamman, J.H. \& Kotzé, A.F. (2003). Evaluation of the mucoadhesive properties of N-trimethyl chitosan chloride. Drug Dev. Ind. Pharm., Vol. 29, pp. 61-69.

Sultana, Y.; Aquil, M. \& Ali, A. (2006). Ion-activated Gelrite ${ }^{\circledR}$-based in situ ophthalmic gels of pefloxacin mesylate: Comparison with conventional eye drops. Drug Delivery, Vol. 13, pp. 215-219.

Taravella, M.J.; Balentine, J.; Young, D.A. \& Stepp, P. (1999). Collagen shield delivery of ofloxacin to the human eye. Cataract Refract. Surg., Vol. 25, pp. 562-565.

Taylor, L.D. \& Ceranaowski, L.D. (1975). Preparation of film exhibiting a balanced temperature dependence to permeation by aqueous solutions-A study of lower consolute behavior. J. Polym. Sci., Polym. Chem. Ed., Vol. 13, pp. 2551-2570.

Thanou, M.; Florea, B.I.; Langemeyer, M.W.E.; Verhoef, J.C. \& Junginger, H.E. (2000). Ntrimethyl chitosan chloride (TMC) improves the intestinal permeation of the peptide drug buserelin in vitro (Caco-2 cells) and in vivo (rats). Pharm. Res., Vol. 17, pp. 27-31.

Thanou, M.; Nihot, M.T.; Jansen, M.; Verhoef, J.C. \& Junginger, H.E. (2001). Mono-Ncarboxymethyl chitosan (MCC), a polyampholytic chitosan derivative, enhances the intestinal absorption of low molecular weight heparin across intestinal epithelia in vitro and in vivo. J. Pharm. Sci., Vol. 90, pp. 38-46.

Uccello-Barretta, G.; Nazzi, S.; Zambito, Y.; Di Colo, G.; Balzano, F. \& Sansò, M. (2010). Synergistic interaction between TS-polysaccharide and hyaluronic acid: Implications in the formulation of eye drops. Int. J. Pharm, Vol. 395, pp. 122-131.

Xu-Bo, Y.; Yan-Bo, Y.; Wei, J.; Jie, L.; En-Jiang, T.; Hui-Ming, S.; Ding-Hai, H.; Xiao-Yan, Y.; Hong, L. S. \& Jing., S. (2008). Preparation of rapamycin-loaded chitosan/PLA nanoparticles for immunosuppression in corneal transplantation. Int. J. Pharm., Vol. 349, pp. 241-248.

Wei, G.; Ding, P.T.; Zheng, J.M. \& Lu, W.Y. (2006). Pharmacokinetics of timolol maleate in aqueous humor sampled by microdialysis after topical administration of thermosetting gels. Biomed. Chromatogr., Vol. 20, pp. 67-71.

Winfield, A.J.; Jessiman, D.; Williams, A. \& Esakowitz, L. (1990). A study of the causes of non-compliance by patients prescribed eyedrops. Br. J. Ophthalmol., Vol. 74, pp. 477480.

Zambito, Y.; Zaino, C. \& Di Colo, G. (2006a). Effects of N-trimethylchitosan on transcellular and paracellular transcorneal drug transport. Eur. J. Pharm. Biopharm., Vol. 64, pp. 16-25.

Zambito, Y.; Uccello-Barretta, G.; Zaino, C.; Balzano, F. \& Di Colo, G.(2006b). Novel transmucosal absorption enhancers obtained by aminoalkylation of chitosan. Eur. J. Pharm. Sci., Vol. 29, pp. 460-469.

Zambito, Y.; Zaino, C.; Burchielli, S.; Carelli, V.; Serafini, M. F. \& Di Colo, G. (2007). Novel quaternary ammonium chitosan derivatives for the promotion of intraocular drug absorption. J. Drug Deliv. Sci. Technol., Vol. 17, pp. 19-24.

Zambito, Y.; Zaino, C.; Uccello-Barretta, G.; Balzano, F. \& Di Colo, G. (2008). Improved synthesis of quaternary ammonium-chitosan conjugates $\left(\mathrm{N}^{+}-\mathrm{Ch}\right)$ for enhanced intestinal drug permeation. Eur. J. Pharm. Sci., Vol. 33, pp. 343-350. 
Zambito, Y.; Fogli, S.; Zaino, C.; Stefanelli, F.; Breschi, M.C. \& Di Colo, G. (2009). Synthesis, characterization and evaluation of thiolated quaternary ammonium-chitosan conjugates for enhanced intestinal drug permeation. Eur. J. Pharm. Sci., Vol. 38, pp. 112-120.

Zambito, Y. \& Di Colo, G. (2010). Thiolated quaternary ammonium-chitosan conjugates for enhanced precorneal retention, transcorneal permeation and intraocular absorption of dexamethasone. Eur. J. Pharm. Biopharm., Vol. 75, pp. 194-199. 


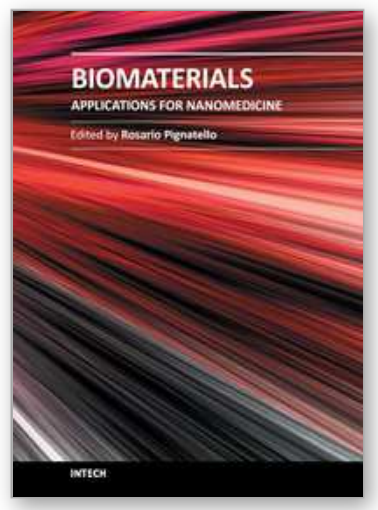

\author{
Biomaterials Applications for Nanomedicine \\ Edited by Prof. Rosario Pignatello
}

ISBN 978-953-307-661-4

Hard cover, 458 pages

Publisher InTech

Published online 16, November, 2011

Published in print edition November, 2011

These contribution books collect reviews and original articles from eminent experts working in the interdisciplinary arena of biomaterial development and use. From their direct and recent experience, the readers can achieve a wide vision on the new and ongoing potentialities of different synthetic and engineered biomaterials. Contributions were selected not based on a direct market or clinical interest, but on results coming from a very fundamental studies. This too will allow to gain a more general view of what and how the various biomaterials can do and work for, along with the methodologies necessary to design, develop and characterize them, without the restrictions necessary imposed by industrial or profit concerns. Biomaterial constructs and supramolecular assemblies have been studied, for example, as drug and protein carriers, tissue scaffolds, or to manage the interactions between artificial devices and the body. In this volume of the biomaterial series have been gathered in particular reviews and papers focusing on the application of new and known macromolecular compounds to nanotechnology and nanomedicine, along with their chemical and mechanical engineering aimed to fit specific biomedical purposes.

\title{
How to reference
}

In order to correctly reference this scholarly work, feel free to copy and paste the following:

Ylenia Zambito and Giacomo Di Colo (2011). Polysaccharides as Excipients for Ocular Topical Formulations, Biomaterials Applications for Nanomedicine, Prof. Rosario Pignatello (Ed.), ISBN: 978-953-307-661-4, InTech, Available from: http://www.intechopen.com/books/biomaterials-applications-for-nanomedicine/polysaccharidesas-excipients-for-ocular-topical-formulations

\section{INTECH}

open science | open minds

\section{InTech Europe}

University Campus STeP Ri

Slavka Krautzeka 83/A

51000 Rijeka, Croatia

Phone: +385 (51) 770447

Fax: +385 (51) 686166

www.intechopen.com

\section{InTech China}

Unit 405, Office Block, Hotel Equatorial Shanghai

No.65, Yan An Road (West), Shanghai, 200040, China

中国上海市延安西路65号上海国际贵都大饭店办公楼 405 单元

Phone: +86-21-62489820

Fax: +86-21-62489821 
(C) 2011 The Author(s). Licensee IntechOpen. This is an open access article distributed under the terms of the Creative Commons Attribution 3.0 License, which permits unrestricted use, distribution, and reproduction in any medium, provided the original work is properly cited. 